
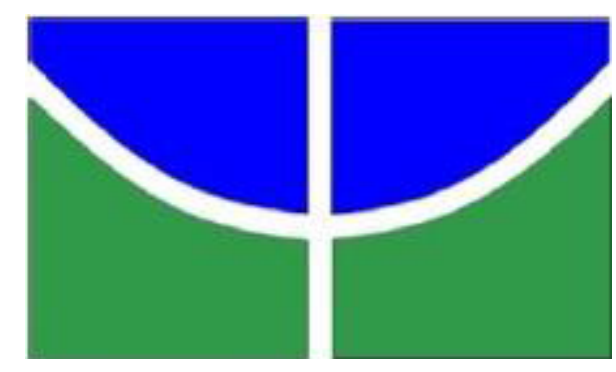

UNIVERSIDADE DE BRASÍLIA

Faculdade de Agronomia e Medicina Veterinária

Programa de Pós-Graduação em Saúde Animal

\title{
PERFIL METABÓLICO DURANTE O PERIPARTO DE OVELHAS DA RAÇA SANTA INÊS COM GESTAÇÃO SIMPLES E MÚLTIPLA
}

ROBERTA TAVARES MOREIRA

DISSERTAÇÃO DE MESTRADO

EM SAÚDE ANIMAL

BRASÍLIA/DF

NOVEMBRO/2014 

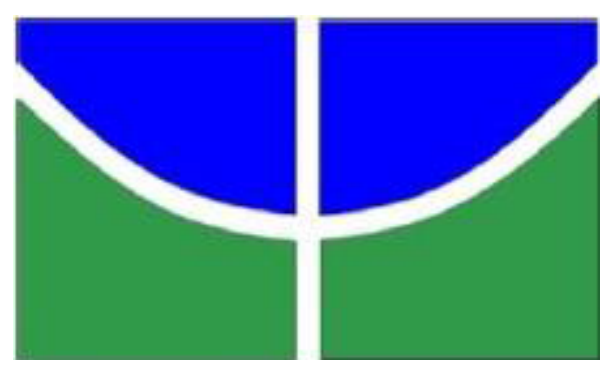

UNIVERSIDADE DE BRASÍLIA

Faculdade de Agronomia e Medicina Veterinária

Programa de Pós-Graduação em Saúde Animal

\section{PERFIL METABÓLICO DURANTE O PERIPARTO DE OVELHAS DA RAÇA SANTA INÊS COM GESTAÇÃO SIMPLES E MÚLTIPLA}

ROBERTA TAVARES MOREIRA

ORIENTADOR: JOSÉ RENATO JUNQUEIRA BORGES

DISSERTAÇÃO DE MESTRADO

EM SAÚDE ANIMAL

BRASÍLIA/DF

NOVEMBRO/2014 
UNIVERSIDADE DE BRASÍLIA

PERFIL METABÓLICO DURANTE O PERIPARTO DE OVELHAS DA RAÇA SANTA INÊS COM GESTAÇÃO SIMPLES E MÚLTIPLA

ROBERTA TAVARES MOREIRA

DISSERTAÇÃO DE MESTRADO SUBMETIDA AO PROGRAMA DE PÓS-GRADUAÇÃO EM SAÚDE ANIMAL, COMO PARTE DOS REQUISITOS NECESSÁRIOS A OBTENÇÃO DO GRAU DE MESTRE EM SAÚDE ANIMAL

APROVADO POR:

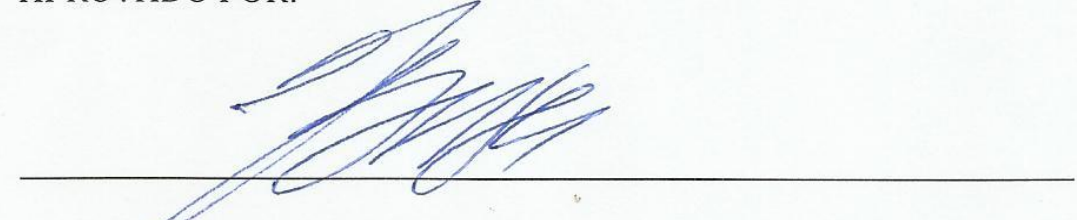

JOSÉ RENATO JUNQUEIRA BORGES, DOUTOR (UNB)

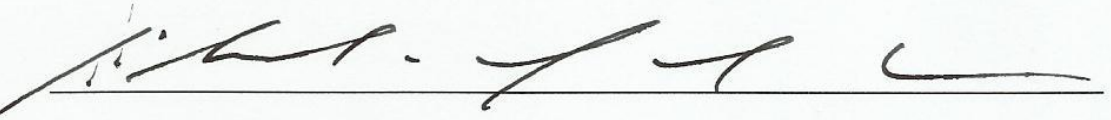

EDUARDO MAURÍCIO MENDES DE LIMA, DOUTOR (UNB)

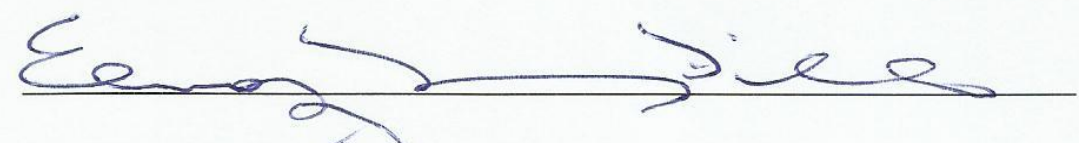

ELIAS JORGE FA\&URY EILHO, DOUTOR (UFMG) 
MOREIRA, R. T. Perfil metabólico durante o periparto de ovelhas da raça Santa Inês com gestação simples e múltipla. Brasília: Faculdade de Agronomia e Veterinária, Universidade de Brasília, 2014, 26p. Dissertação de Mestrado.

Documento formal, autorizando reprodução desta dissertação de Mestrado para empréstimo ou comercialização, exclusivamente para fins acadêmicos; foi passado pelo autor à Universidade de Brasília e acha-se arquivado na secretaria do Programa. 0 autor reserva para si os outros direitos autorais, de publicação. Nenhuma parte desta dissertação de mestrado pode ser reproduzida sem a autorização por escrito do autor. Citações são estimuladas, desde que citada a fonte.

Moreira, Roberta Tavares

Perfil metabólico durante o periparto de ovelhas da raça Santa Inês com gestação simples e múltipla/Roberta Tavares Moreira

Orientação de José Renato Junqueira Borges.

Brasília, 2014. 26p.: il.

Dissertação de mestrado (M) - Universidade de Brasília/ Faculdade de Agronomia e Veterinária, 2014.

1. Ovinos 2. Metabolismo 3. Dieta 4. Parto 5. Toxemia da Prenhez. I. Borges, J. R. J. II. Doutor 


\section{AGRADECIMENTOS}

Obrigada, meu Deus, pela realização desse sonho. Por estar comigo em todos os momentos, guiando cada passo, por me capacitar e fortalecer. Obrigada, Pai, por me permitir subir mais este degrau!

Aos meus pais, Olicio e Eliane, por fazerem de mim quem sou hoje, pelos ensinamentos, por serem essenciais à formação de meu caráter. Por me ensinarem a acreditar em mim, não desistir de meus sonhos, a batalhar para conquistar meus objetivos, e sempre, a ter fé. À minha maninha Fernanda, por me apoiar e incentivar sempre, pelo amor e carinho, pelo exemplo de coragem. Amo muito vocês! A todos meus familiares, pelas palavras amigas e por entenderem as ausências necessárias.

Ao professor José Renato, que, alem de grande orientador, mostrou-se um exímio psicólogo. Obrigada por ter confiado em meu trabalho, por ter me instruído e pelas palavras amigas nas horas em que batia o medo. Foi uma honra tê-lo como orientador!

Aos amigos, pelo incentivo. Em especial ao Zé Luis, pelos conselhos, palavras de ânimo e carinho e por ser o maior incentivador desse projeto.

À Lorena, meu braço direito durante toda a fase experimental, desde a revolta das ovelhas ao frio congelante do laboratório! Obrigada, de coração! E não poderia deixar de agradecer a todos que me auxiliaram durante as coletas, estagiários, residentes, alunos... vocês foram essenciais ao sucesso desse trabalho!

Ao professor Eduardo, pelas inúmeras ajudas, conselhos e por disponibilizar o laboratório. À Fabieni, por ter me fornecido treinamento para a realização das análises bioquímicas. Ao Léo e Caíque, por me ajudarem imensamente nas análises estatísticas.

À fazenda Sanga Puitã por abrir as portas e permitir a realização desse projeto ao disponibilizar os animais.

Ao Instituto Federal de Brasília, por possibilitar a liberação parcial para que pudesse me dedicar ao mestrado.

Enfim, a todos que participaram direta ou indiretamente da realização desse sonho, aos que torceram por mim! Essa conquista é nossa! 


\section{SUMÁRIO}

\section{Página}

LISTA DE ABREVIATURAS................................................................................................................ $\quad \mathbf{7}$

LISTA DE FIGURAS .......................................................................................................................... $\quad 8$

LISTA DE TABELAS........................................................................................................................... $\quad 9$

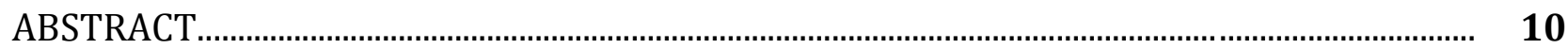

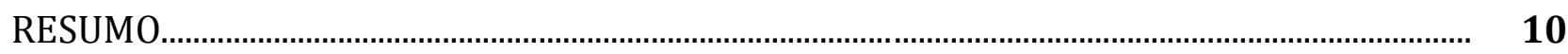

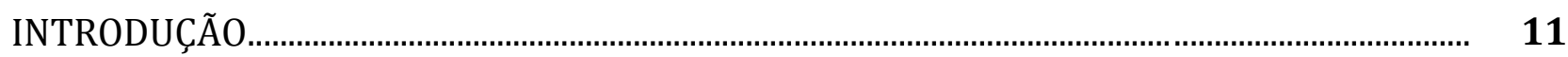

MATERIAL E MÉTODOS............................................................................................................... $\quad 11$

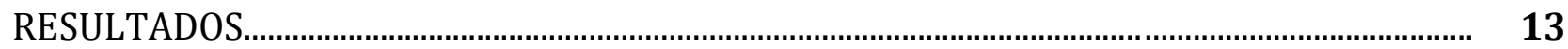

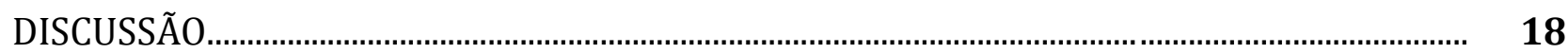

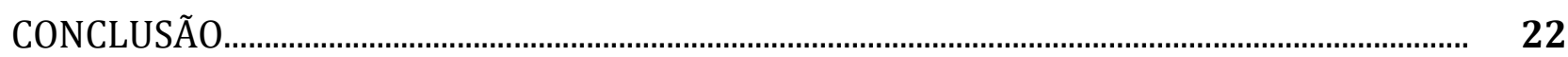

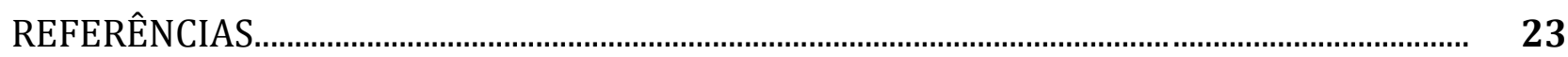

ANEXOS 


\begin{tabular}{ll} 
ALB & Albumina \\
AST & Aspartatoaminotransferase \\
BHB & Beta hidroxibutirato \\
Ca & Cálcio \\
CRT & Creatinina \\
dL & Decilitro \\
DP & Desvio padrão da Média \\
EC & Escore Corporal \\
GG & Gestação Gemelar \\
GGT & Gama glutamiltransferase \\
GLB & Globulina \\
GLI & Glicose \\
GS & Gestação simples \\
Mg & Magnésio \\
mg & Miligrama \\
mmol & Milimol \\
MS & Matéria Seca \\
NDT & Nutrientes Digestíveis Totais \\
P & Fósforo \\
PB & Proteína Bruta \\
PROT & Proteínas totais \\
rpm & Rotações por minuto \\
U & Unidades internacionais \\
UR & Uria \\
\hline
\end{tabular}




\section{LISTA DE FIGURAS}

Página

Figura 1 Perfil Metabólico energético - Níveis séricos médios das variáveis 14 Glicose (A) e BHB (B) para os grupos Gestação Simples e Gemelar durante o periparto.

Figura 2 Perfil Metabólico mineral - Níveis séricos médios das variáveis Cálcio (A), Fósforo (B) e Magnésio (C) para os grupos Gestação Simples e Gemelar durante o periparto.

Figura 3 Perfil Metabólico Protéico - Níveis séricos médios das variáveis Uréia (A), Creatinina (B), proteínas Totais (C), Albumina (D) e Globulina (E) para os grupos Gestação Simples e Gemelar durante o periparto.

Figura 4 Perfil Hepático - Níveis séricos médios das variáveis AST (A) e GGT (B) para os grupos Gestação Simples e Gemelar durante o periparto. 


\section{LISTA DE TABELAS}

Página

Tabela 1 Composição bromatológica da dieta oferecida diariamente por animal, no período da seca, tendo silagem de milho como base volumosa, ração produzida na propriedade como base do concentrado (51\% fubá de milho, 25\% farelo de soja, $20 \%$ farelo de trigo e 4\% núcleo comercial Guabi®) e sal Ovinofos Turtuga ${ }^{\circledR}$ como fonte mineral.

Tabela 2 Classificação de Escore Corporal em ovinos - segundo McManus et al., 2010.

Tabela 3 Tempos e intervalos considerados para a determinação do perfil metabólico de ovelhas da raça Santa Inês no Periparto.

Tabela 4 Valores Médios e Desvio Padrão da Média para as variáveis estudadas na avaliação de perfil metabólico em ovelhas Santa Inês com Gestação Simples durante o periparto.

Tabela 5 Valores médios e Desvio Padrão da Média para as variáveis 16 estudadas na avaliação de perfil metabólico em ovelhas Santa Inês com Gestação Gemelar durante o periparto.

Tabela 6 Freqüência de Escore Corporal no grupo Gestação Simples.

Tabela 7 Freqüência de Escore Corporal no grupo Gestação Gemelar. 


\title{
Perfil metabólico durante o periparto de ovelhas da raça Santa Inês com gestação simples e múltipla
}

Roberta Tavares Moreira1* ${ }^{*}$ José Renato J. Borges ${ }^{1}$.

\begin{abstract}
Moreira, R. T., Borges, J. R. J. [Metabolic profile during the periparturient ewes Santa Ines with simple and multiple pregnancy]. Perfil metabólico durante o periparto de ovelhas da raça Santa Inês com gestação simples e múltipla. Pesquisa Veterinária Brasileira 00(0):00-00. Programa de Pós-Graduação em Saúde Animal, Faculdade de Agronomia e Medicina Veterinária, Universidade de Brasília (UNB), ICC Sul, Campus Universitário Darcy Ribeiro, Cx. Postal 4508, Brasília, DF 70760-701, Brasil. E-mail: betatmoreira@yahoo.com.br

The metabolic profile represents an important tool in the diagnostic of metabolic diseases and in the nutritional monitoring of production animals. The main aim of this study is to evaluate the body scores and metabolic profile of sheep of the Santa Inês breed in a system of semi-confinement, during the peri-parturient. The body scores and metabolic profile were analysed between animals with single and multiple pregnancies. Fifty-five sheep of the Santa Inês breed were recruited for this study, of those, 43 with single pregnancy and 12 with twin pregnancies. The animals were submitted to blood collection and analyses of body score (BS) weekly, from the end of third month of pregnancy until one month postpartum, and those were analysed 10 times during this research. About the analyses throughout weeks, the study found different values to the variables Glucoses, BHB, Calcium, Phosphorus, Urea, and Creatinine for the Single Pregnancy (SP) and Twin Pregnancies (TP) groups $(p<0,005)$. Moreover, distinct rates of Magnesium was noticed in the Single Pregnancy group $(p<0,005)$. The week of birth and subsequent weeks, showed statistically different values of those from the weeks leading up to the birth in most of the variables studied. There was no significant difference in the comparison between the SP and TP groups for the parameters evaluated. In both groups, there were a decrease in the female body score, with a reduction in the proportion of animal with BS 3 and 4 associated, and concomitant increase of animals with BS 2 proportion.
\end{abstract}

INDEX TERMS: Sheep, Metabolism, Diet, Parturition, Pregnancy Toxaemia.

RESUMO- O perfil metabólico é uma importante ferramenta no diagnóstico de doenças metabólicas e monitoramento nutricional de animais de produção. Este trabalho teve por objetivo avaliar o escore corporal e perfil metabólico de ovelhas da raça Santa Inês criadas em sistemas de semi-confinamento, ao longo do periparto, comparando estes parâmetros entre animais com gestação simples e gestação múltipla. Cinqüenta e cinco ovelhas da raça Santa Inês, sendo 43 com gestação simples e 12 com gestação gemelar, foram submetidas a coletas de sangue e avaliação do escore corporal semanalmente, a partir do final do terceiro mês de gestação até um mês pós-parto, no total de 10 avaliações. Observou-se diferenças na comparação entre semanas para as variáveis Glicose, BHB, Cálcio, Fósforo, Uréia e Creatinina para os grupos Gestação Simples (GS) e Gestação Gemelar (GG), alem de diferenças nos níveis de Magnésio para o primeiro grupo $(\mathrm{p}<0,005)$. A semana do parto e semana subseqüentes apresentaram valores estatisticamente diferentes das semanas que precederam ao parto na maioria das variáveis estudadas. Não houve diferença significativa na comparação entre os grupos GS e GG para os parâmetros avaliados. Em ambos os grupos, houve redução no escore corporal das fêmeas acompanhadas, com uma queda na proporção de animais com EC 3 e 4 associada e concomitante crescimento na proporção de animais com EC 2.

TERMOS DE INDEXAÇÃo: Ovinos. Metabolismo. Dieta. Parto. Toxemia da Prenhez

\footnotetext{
Recebido em

Aceito para publicação em..........

1Faculdade de Agronomia e Medicina Veterinária, universidade de Brasília (UNB), ICC Ala Sul, Campus Darcy Ribeiro, Cx Postal 4508, Brasília, DF 70760-701, Brasil.*Autor para correspondência: betatmoreira@yahoo.com.br
} 


\section{INTRODUÇÃo}

A ovinocultura de corte vem ocupando espaço cada vez mais expressivo na pecuária brasileira ao longo dos últimos anos, tendo em vista o aumento do consumo pelo mercado nacional. Segundo Ávila et al. (2013), o consumo interno de carne ovina saltou de 70 mil toneladas para mais de 120 mil toneladas entre 2003 e 2006, volume este superior ao produzido pela ovinocultura nacional, estimulando e alavancando a produção da espécie na agropecuária brasileira. De acordo com o ultimo censo agropecuário (IBGE, 2006), o rebanho ovino era composto por 13.856 .747 cabeças, com as regiões Nordeste e Sul responsáveis pela maior concentração dos rebanhos. Neste mesmo cenário, a região centro-oeste ocupava a terceira colocação em área de concentração da espécie. No Distrito Federal, o rebanho ovino totalizava cerca de 16 mil cabeças, dessas, $78 \%$ correspondiam à raça Santa Inês, raça de maior expressão na produção ovina do Distrito Federal, segundo levantamento da EMATER-DF, fato que reflete o cenário nacional.

Mesmo com o grande potencial de crescimento, uma importante barreira à expansão da ovinocultura são as doenças metabólicas que acometem principalmente ovelhas em período produtivo, doenças estas geralmente diagnosticadas e tratadas tardiamente, culminando em perdas e prejuízos aos sistemas de produção. As doenças metabólicas são caracterizadas por um desequilíbrio entre o ingresso e o metabolismo de nutrientes (glicídios, proteínas, minerais e água) no organismo animal, onde o aporte de alimentos não é suficiente para atender à demanda nutricional de manutenção e produção (WITTWER, 2000).

A toxemia da prenhez é a doença metabólica de maior relevância econômica que acomete ovinos. Ocorre durante as ultimas seis semanas de gestação, quando o(s) feto(s) alcança(m) cerca de $70 \%$ de seu crescimento (MELO et al., 2009). É considerada como uma das mais importantes doenças causadoras de morte em ovelhas gestantes, pela difícil resposta ao tratamento, onde grande parte das fêmeas acometidas vão a óbito, caracterizando a alta letalidade (SCHILD, 2007; RADOSTITS et al., 2002). No Distrito Federal, a doença foi elencada como a sétima mais freqüente na espécie ovina, entre os anos de 2001 e 2006, nos atendimentos do Hospital Veterinário da UNB (Borges et al., 2007). Considerando-se a importância clínica e econômica da Toxemia da Prenhez, o diagnóstico precoce desta doença é primordial ao sucesso do tratamento. Para isso, a mensuração de parâmetros metabólicos que possibilitem resultados rápidos, simples execução e acesso ao profissional veterinário, como os dosadores portáteis de glicose e beta-hidroxibutirato, por exemplo, torna-se peça fundamental ao controle do perfil metabólico de rebanhos ovinos.

A doença caracteriza-se por um quadro de hipoglicemia associado à acidose metabólica, cetose, esteatose hepática, sintomas neurológicos e digestivos, quadro clínico este que, quando não tratado ou tratado tardiamente, leva a fêmea acometida a morte (PUGH, 2002). Fêmeas com gestações múltiplas muito magras ou muito gordas são mais propensas a desenvolver a toxemia da prenhez (MERCK, 2005). É subdividida em dois tipos, de acordo com o escore corporal da fêmea acometida, sendo o Tipo I relacionado com a subalimentação e o Tipo II com a superalimentação. Quanto maior o número de fetos em gestação e quanto mais próximo ao parto, maiores são as demandas energéticas para manutenção materna e fetal, e conseqüentemente maiores são as chances de desordens metabólicas, se comparadas às fêmeas gestantes de fetos únicos, sendo o terço final da gestação o período mais crítico para esta doença (ORTOLANI e BENESI, 1989).

Alem da toxemia da gestação, doenças carenciais minerais, como hipocalcemia, também merecem atenção durante o periparto em ovinos. A hipocalcemia em ovelhas ocorre nas formas clínica e subclínica, nas ultimas semanas de gestação até duas semanas pós-parto, durante o processo de mineralização do esqueleto do feto/recém nascido. Apesar da baixa incidência (em torno de 5\%), geralmente coexiste com quadros de toxemia da gestação. A hipomagnesemia, outro transtorno metabólico mineral, apesar rara na espécie ovina, esta atrelada principalmente a dieta, tendo em vista a baixa capacidade de mobilização de reserva perante necessidades (BROZOS et al., 2011).

A avaliação do perfil metabólico tem sido primordial ao diagnóstico precoce de doenças metabólicas nos animais de produção, uma vez que permite o monitoramento das vias metabólicas de energia, proteínas e minerais, e da higidez de órgãos vitais à produção, como o fígado, servindo como indicador do balanço metabólico (WITTWER, 2000; RIBEIRO et al. 2003). Dessa forma, o conhecimento dos parâmetros relativos ao perfil metabólico durante o período gestacional de pequenos ruminantes, torna-se uma base segura e de fácil execução ao veterinário clínico para o diagnóstico e tratamento precoces da toxemia da prenhez, evitando grandes prejuízos nos sistemas de produção.

Considerando a escassez de literaturas que abordam o perfil metabólico de ovelhas gestantes da raça Santa Inês, e dada a importância do conhecimento destes fatores para o bom manejo nutricional em um período tão crítico de produção, este trabalho teve por objetivo avaliar o escore corporal e perfil metabólico de ovelhas da raça Santa Inês criadas em sistemas de semi-confinamento, ao longo do periparto, comparando estes parâmetros entre animais com gestação simples e gestação múltipla.

\section{MATERIAL E MÉTODOS}

Este trabalho foi aprovado pela Comissão de Ética no Uso Animal (CEUA) do Instituto de Ciências Bioló- 
gicas da UNB, sob protocolo no55245/2013 (anexo 1).

\section{Grupo experimental}

Foram utilizadas cinqüenta e cinco (55) ovelhas adultas, multíparas, da raça Santa Inês, provenientes de um sistema de produção semi-intensivo de ovinos, Fazenda Sanga Puitã, localizada na região do PAD-DF, divisa entre o Distrito Federal e o estado de Goiás, a qual respondeu favoravelmente ao Termo de Consentimento e livre esclarecimento (anexo 2) ao uso dos animais em atividade experimental.

A fazenda, composta por um rebanho de 900 ovinos, mantinha os animais da raça Santa Inês em sistema de semi-confinamento, manejados a pasto no período das águas (sistema agro-floresta Eucalipto/Brchiaria decumbens para fêmeas não prenhes sem borrego ao pé e fêmeas gestantes, e piquetes de Tyfton 85 para fêmeas paridas com borrego ao pé) e suplementados com silagem de milho e concentrado durante o período da seca. 0 sal mineral era disposto à vontade aos animais. Não havia distinção de dieta por categoria ou faixa etária, sendo que todos os animais do rebanho eram submetidos às mesmas bases alimentares. Durante o período da seca, período este em que se passou a fase experimental de campo deste trabalho, os animais recebiam silagem misturada ao concentrado duas vezes ao dia, às 7 e 16 horas (composição da dieta durante a fase experimental Tabela 1).

Tabela 1. Composição bromatológica da dieta oferecida diariamente por animal, no período da seca, tendo silagem de milho como base volumosa, ração produzida na propriedade como base do concentrado $(51 \%$ fubá de milho, 25\% farelo de soja, $20 \%$ farelo de trigo e $4 \%$ núcleo comercial Guabi®) e sal Ovinofos Turtuga ${ }^{\circledR}$ como fonte mineral:

\begin{tabular}{cccccc}
\hline Fonte alimentar & MS (Kg) & NDT (Kg) & PB (g) & Ca (g) & P (g) \\
\hline Silagem de milho & 1.91 & 1.15 & 150 & 6 & 4 \\
Ração & 0.09 & 0.06 & 166 & 1 & 0.6 \\
Sal mineral & 0.02 & 0 & 0 & 2.4 & 1.7 \\
Total & $\mathbf{2 . 0 2}$ & $\mathbf{1 . 2 1}$ & $\mathbf{3 1 6}$ & $\mathbf{9 . 4}$ & $\mathbf{6 . 3}$ \\
\hline
\end{tabular}

Um mês após o término da estação de monta, o qual se deu entre abril e junho de 2013, os lotes de ovelhas em estação reprodutiva foram submetidos à avaliação ultrassonográfica, a partir da técnica transparietal, para diagnóstico gestacional. As fêmeas adultas com prenhez confirmada aptas a comporem o grupo experimental foram selecionadas aleatoriamente até atingirem o número de animais necessário para a pesquisa. Todas as fêmeas pertencentes ao grupo experimental foram identificadas com colar de cor branca e brinco com numeração que as diferissem do restante do rebanho.

\section{Coleta e processamento das amostras}

A partir do terceiro mês de gestação, estimado pelo período de estação de monta, as ovelhas selecionadas passaram a ser submetidas a coletas semanais de sangue em tubos Vacutainer® sem anticoagulante, por venopunção da jugular, para obtenção de soro necessário às análises bioquímicas, no volume de $20 \mathrm{ml}$ por animal. Também foram submetidas à avaliação de escore corporal (EC), por meio de inspeção geral e palpação dos processos dorsal e transverso das vértebras lombares e fossa ísquio-caudal, classificados segundo McManus et al. (2010) (Tabela 2).

Tabela 2. Classificação de Escore Corporal em ovinos - segundo McManus et al., 2010

\begin{tabular}{cc}
\hline Escore & Classificação \\
\hline 1 & Extremamente emaciada \\
2 & Magra \\
3 & Boa \\
4 & Gorda \\
5 & Obesa \\
\hline
\end{tabular}

O período total de coletas e avaliação de escore corporal perdurou da quinta semana pré-parto até a quarta semana pós-parto, num total de 10 avaliações por animal (Tabela 3), entre os meses de julho e novembro, coincidente com parte da estação de nascimento na propriedade (setembro a novembro). 
Tabela 3. Tempos e intervalos considerados para a determinação do perfil metabólico de ovelhas da raça Santa Inês no Periparto

\begin{tabular}{cl}
\hline Tempo & \multicolumn{1}{c}{ Intervalo } \\
\hline $\operatorname{Pr} 5$ & 5 semanas pré-parto \\
$\operatorname{Pr} 4$ & 4 semanas pré-parto \\
$\operatorname{Pr} 3$ & 3semanas pré-parto \\
$\operatorname{Pr} 2$ & 2 semanas pré-parto \\
$\operatorname{Pr} 1$ & 1 semana pré-parto \\
P 0 & Semana do parto \\
Po 1 & 1 semana pós-parto \\
Po 2 & 2 semanas pós-parto \\
Po 3 & 3 semanas pós-parto \\
Po 4 & 4 semanas pós-parto \\
\hline
\end{tabular}

\section{Parto Simples x Parto gemelar}

Não foi possível identificar a existência de gestação simples ou gemelar no momento do exame ultrassonográfico, tendo em vista que alguns animais já estavam em fase gestacional superior a um mês, momento este onde era impossível ter certeza do número de fetos gestantes. Logo, a separação dos grupos experimentais Gestação Simples (GS) e Gestação Gemelar (GG) só se deu no momento do parto. Dessa forma, os grupos Gestação Simples e Gestação Gemelar foram compostos por 43 e 12 ovelhas, respectivamente.

\section{Análises bioquímicas}

Imediatamente após a coleta de sangue, utilizou-se parte das amostras para avaliação, in loco, dos níveis de Glicose (GLI) e Beta-hidroxibutirato (BHB), por intermédio do medidor portátil Optimum Xceed®. Os tubos contendo as amostras de sangue, previamente identificados, foram acondicionados em caixas isotérmicas com gelo até o fim das coletas e posterior transporte.

No Laboratório de Anatomia Veterinária da FAV/UNB, as amostras eram centrifugadas (centrífuga Centribio $($ ), no mesmo dia das coletas, à 3000rpm por 10 minutos para extração de soro, o qual era aliquotado em tubos Eppendorf® de $2 \mathrm{ml}$ (no mínimo 4 alíquotas por animal por coleta) e mantido congelado à $-18^{\circ} \mathrm{C}$ até o momento da realização das demais análises bioquímicas, as quais se procederam ao fim de toda a seqüência de coletas.

As analises bioquímicas também foram realizadas no Laboratório de Anatomia Veterinária da FAV/UNB, as quais incluíram dosagem de Proteínas Totais (PROT), Albumina (ALB), Globulinas (GLB), Cálcio (Ca), Fósforo (P), Magnésio (Mg), Uréia (UR), Creatinina (CRT), e a medição da atividade das enzimas Aspartatoaminotranferase (AST) e Gama glutamiltransferase (GGT). Todas as análises elencadas anteriormente, exceto a dosagem de globulinas, foram realizadas a partir de Kits comerciais Labtest $₫$, em espectrofotômetro colorimétrico semi-automático (BioPlus BIO $2000 ®$ ). A dosagem de globulina foi realizada a partir da diferença dos valores de dosagem de proteínas totais e albumina.

A partir dos resultados obtidos na dosagem de BHB, realizou-se levantamento de possíveis quadros subclínicos de Cetose, considerando-se valores entre 0.8 e $3 \mathrm{mmol} / \mathrm{L}$ da variável como indicativo da doença, segundo Andrews (1997) e Merck (2005).

\section{Análises estatísticas}

Os resultados obtidos no estudo foram expressos a partir de análise descritiva através de média e desvio padrão da média, em um delineamento inteiramente casualizado com parcelas subdivididas, sendo os tratamentos (GS e GG) as parcelas, e os tempos as subparcelas.

Os dados obtidos através das avaliações de perfil bioquímico foram analisados pelo programa Graphpad Prism 6.01., por análise de variância seguida do teste de Holm Sidak's, para dados com distribuição Normal, e Teste de Friedman, para dados que não seguiram o padrão Normal, traçando-se comparações múltiplas nas diversas variáveis analisadas entre semanas para o mesmo grupo. Na comparação entre o grupo Gestação Simples e Gestação Gemelar utilizou-se o Teste t Pareado, para parâmetros com distribuição Normal e Teste de Wilcoxon para valores sem distribuição Normal. Em todos os casos, considerou-se p $\leq 0,05$ como estatisticamente significativo.

\section{RESULTADOS}

Os valores médios e Desvio Padrão da Média (DP) para as variáveis estudadas na avaliação do perfil metabólico de ovelhas da raça Santa Inês com gestação simples e gemelar (nos tempos Pr5, Pr4, Pr3, Pr2, Pr1, P0, 
Po1, Po2, Po3 e Po4) encontram-se nas tabelas 4 e 5, respectivamente.

A partir da análise temporal do grupo GS, durante o periparto, foram observadas diferenças estatísticas nas comparações entre semanas para variáveis Glicose, BHB, Cálcio, Fósforo, Magnésio, Uréia e Creatinina (evidenciado por letras diferentes na mesma linha correspondente da tabela 4). Na análise temporal do grupo GG as diferenças foram observadas nas variáveis Glicose, BHB, Cálcio, Fósforo, Uréia e Creatinina (tabela 5).

Ao avaliar o perfil metabólico energético, os níveis de glicose das ovelhas do grupo GS apresentaram-se mais elevados $(\mathrm{p}<0.05)$ em todo o período pós-parto se comparado ao pré-parto. 0 aumento da glicemia iniciou na semana anterior ao parto (Pr1), mantendo-se estável a partir da semana do parto (P0). Comportamento semelhante foi observado no grupo GG, com níveis de glicose mais altos em todas as semanas pós-parto quando comparadas às semanas correspondentes ao fim da gestação $(\mathrm{p}<0.05)$, e elevação desta variável a partir da semana do parto. Na análise comparativa entre os grupos GS e GG, não foram observadas diferenças estatisticamente significativas.

Na avaliação da variável BHB, para o grupo GS, observou-se elevação nos níveis médios a partir da semana Pr1, com valores mais altos da variável em todas as semanas seguintes se comparados às quatro primeiras semanas avaliadas $(\mathrm{p}<0.05)$. Em GG, níveis mais altos de BHB foram encontrados a partir da semana do parto, observando-se diferença nos valores médios entre as semanas pré e pós parto $(\mathrm{p}<0.05)$. Na comparação entre GS e GG, também não se observou diferença entre os grupos. Durante as dez semanas avaliadas, $37,2 \%$ das ovelhas com gestação simples desenvolveram cetose subclínica, enquanto que no grupo GG, a proporção de animais com o quadro foi de $66,6 \%$.

O perfil metabólico energético, evidenciado pelas curvas de valores médios de glicose e BHB, foi representado na figura 1.

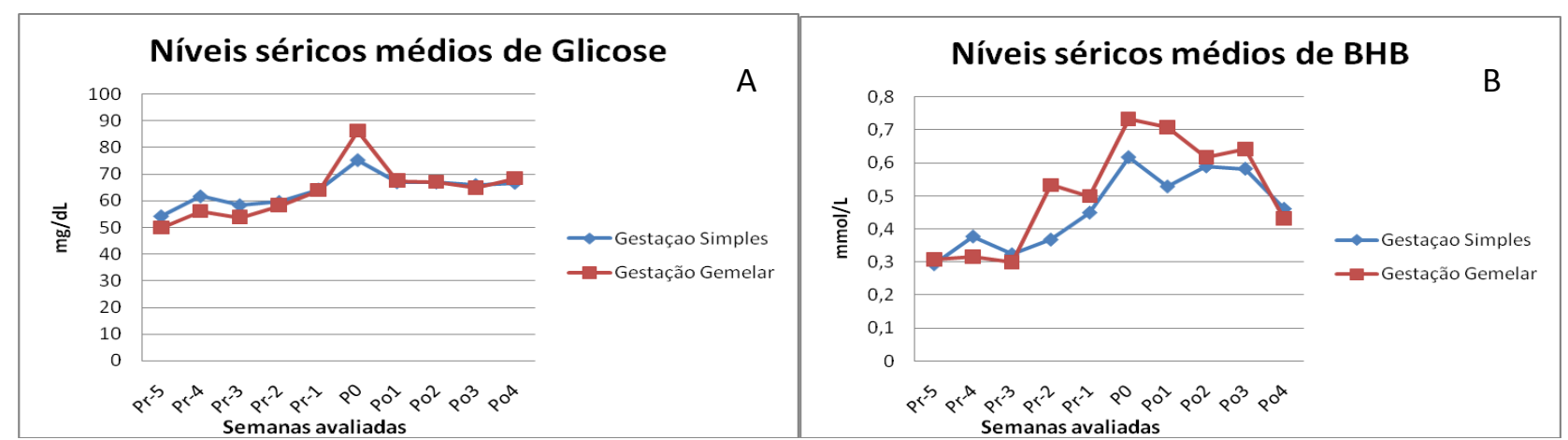

Figura 1- Perfil Metabólico energético - Níveis séricos médios das variáveis Glicose (A) e BHB (B) para os grupos Gestação Simples e Gemelar durante o periparto.

Quanto ao perfil metabólico mineral, na avaliação dos níveis de Cálcio, observou-se, tanto em GS como em GG, valores inferiores da variável nas semanas Po1 a Po4 se comparadas às semanas anteriores $(\mathrm{p}<0.05)$. Na comparação entre os grupos GS e GG, observou-se diferenças na semana do parto ( $p=0.002)$, com o grupo gestação gemelar com níveis inferiores. Em se tratando da variável Fósforo, no grupo GG observou-se níveis decrescentes da variável ao longo das semanas ( $\mathrm{p}<0.05)$. No grupo $G G$, apenas as duas ultimas semanas avaliadas foram inferiores às anteriores $(\mathrm{p}<0.05)$. Nenhuma diferença foi observada no comportamento da variável Fósforo ao longo das semanas entre GS e GG. Na avaliação do mineral Magnésio, as três últimas semanas avaliadas (Po2 a Po4) foram estatisticamente inferiores à semana $\operatorname{Pr} 3(\mathrm{p}<0.05)$. Não houve diferença estatística na comparação entre semanas avaliadas em GG. Na comparação entre os dois grupos pesquisados, também não se observou diferença ao longo das semanas. A figura 2 apresenta curvas de valores médios referente às variáveis estudadas no perfil metabólico mineral.

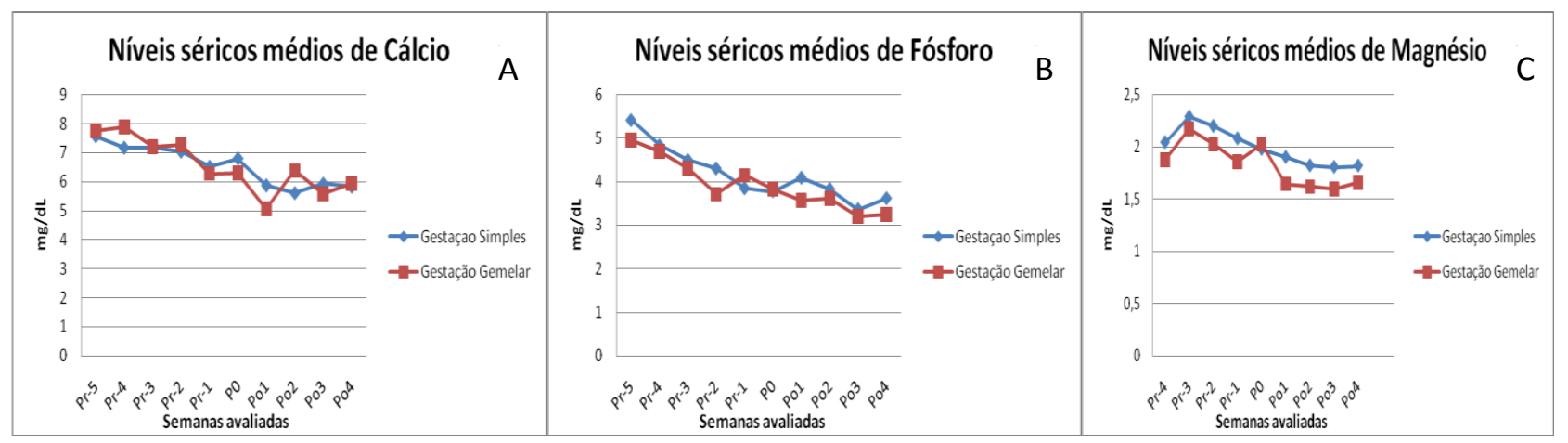

Figura 2- Perfil Metabólico mineral - Níveis séricos médios das variáveis Cálcio (A), Fósforo (B) e Magnésio (C) para os grupos Gestação Simples e Gemelar durante o periparto. 
Tabela 4. Valores Médios e Desvio Padrão da Média para as variáveis estudadas na avaliação de perfil metabólico em ovelhas Santa Inês com Gestação Simples durante o periparto*.

\begin{tabular}{|c|c|c|c|c|c|c|c|c|c|c|}
\hline \multirow{2}{*}{ Variável } & \multicolumn{10}{|c|}{ Semanas avaliadas } \\
\hline & Pr5 & Pr4 & Pr3 & Pr2 & Pr1 & PO & Po1 & Po2 & Po3 & Po4 \\
\hline GLI (mg/dL) & $54,26 \pm 10,48 \mathrm{~A}$ & $61,74 \pm 10,87 \mathrm{~A}$ & $58,40 \pm 11,07 \mathrm{~A}$ & $59,65 \pm 9,84 \mathrm{~A}$ & $64,33 \pm 11,25 \mathrm{AB}$ & $75,35 \pm 17,68 \mathrm{~B}$ & $67,05 \pm 11,09 \mathrm{AB}$ & $66,98 \pm 10,61 \mathrm{AB}$ & $66,00 \pm 12,72 \mathrm{AB}$ & $66,84 \pm 11,81 \mathrm{AB}$ \\
\hline BHB (mmol/L) & $0,29 \pm 0,18 \mathrm{~A}$ & $0,37 \pm 0,26 \mathrm{~A}$ & $0,32 \pm 0,18 \mathrm{~A}$ & $0,37 \pm 0,22 \mathrm{~A}$ & $0,45 \pm 0,22 \mathrm{AB}$ & $0,62 \pm 0,28 \mathrm{~B}$ & $0,53 \pm 0,18 \mathrm{~B}$ & $0,59 \pm 0,19 \mathrm{~B}$ & $0,58 \pm 0,25 \mathrm{~B}$ & $0,46 \pm 0,18 \mathrm{~B}$ \\
\hline $\mathrm{Ca}(\mathrm{mg} / \mathrm{dL})$ & $7,56 \pm 1,06 \mathrm{~A}$ & $7,16 \pm 1,31 \mathrm{~A}$ & $7,18 \pm 1,32 \mathrm{~A}$ & $7,03 \pm 1,29 \mathrm{~A}$ & $6,51 \pm 1,74 \mathrm{~A}$ & $6,79 \pm 1,84 \mathrm{~A}$ & $5,87 \pm 1,63 \mathrm{AB}$ & $5,60 \pm 1,64 \mathrm{~B}$ & $5,92 \pm 1,86 \mathrm{AB}$ & $5,83 \pm 1,70 \mathrm{AB}$ \\
\hline$P(\mathrm{mg} / \mathrm{dL})$ & $5,42 \pm 1,61 \mathrm{~A}$ & $4,84 \pm 1,88 \mathrm{~A}$ & $4,50 \pm 1,66 \mathrm{~A}$ & $4,30 \pm 1,73 \mathrm{AB}$ & $3,85 \pm 1,45 \mathrm{AB}$ & $3,78 \pm 1,42 \mathrm{AB}$ & $4,09 \pm 1,82 \mathrm{AB}$ & $3,83 \pm 1,44 \mathrm{AB}$ & $3,36 \pm 1,51 \mathrm{~B}$ & $3,61 \pm 1,52 \mathrm{~B}$ \\
\hline $\mathrm{Mg}(\mathrm{mg} / \mathrm{dL})$ & $2,14 \pm 0,70 \mathrm{~A}$ & $2,04 \pm 0,62 \mathrm{~A}$ & $2,29 \pm 0,66 \mathrm{~A}$ & $2,20 \pm 0,62 \mathrm{~A}$ & $2,08 \pm 0,52 \mathrm{~A}$ & $1,98 \pm 0,60 \mathrm{~A}$ & $1,90 \pm 0,67 \mathrm{~A}$ & $1,82 \pm 0,79 \mathrm{AB}$ & $1,81 \pm 0,66 \mathrm{AB}$ & $1,82 \pm 0,75 \mathrm{AB}$ \\
\hline UR (mg/dL) & $18,35 \pm 6,66 \mathrm{~A}$ & $16,12 \pm 8,80 \mathrm{~A}$ & $19,56 \pm 8,14 \mathrm{~A}$ & $22,28 \pm 9,55 \mathrm{~A}$ & $26,72 \pm 12,38 \mathrm{AB}$ & $33,58 \pm 15,09 \mathrm{AB}$ & $33,28 \pm 13,93$ B & $33,09 \pm 12,37 \mathrm{~B}$ & $31,14 \pm 11,42$ B & $28,28 \pm 9,55$ B \\
\hline CRT (mg/dL) & $1,13 \pm 0,23 \mathrm{~A}$ & $1,08 \pm 0,24 \mathrm{~A}$ & $1,07 \pm 0,20 \mathrm{~A}$ & $1,01 \pm 0,22 \mathrm{AB}$ & $0,96 \pm 0,22 \mathrm{AB}$ & $0,90 \pm 0,25 \mathrm{~B}$ & $0,87 \pm 0,21 \mathrm{~B}$ & $0,85 \pm 0,27 \mathrm{~B}$ & $0,81 \pm 0,19 \mathrm{~B}$ & $0,77 \pm 0,18$ B \\
\hline PROT (g/dL) & $5,59 \pm 1,32 \mathrm{~A}$ & $5,05 \pm 1,30 \mathrm{~A}$ & $5,15 \pm 1,43 \mathrm{~A}$ & $5,15 \pm 1,12 \mathrm{~A}$ & $5,44 \pm 1,06 \mathrm{~A}$ & $5,36 \pm 1,24 \mathrm{~A}$ & $5,15 \pm 1,28 \mathrm{~A}$ & $4,92 \pm 1,49 \mathrm{~A}$ & $4,90 \pm 1,66 \mathrm{~A}$ & $4,94 \pm 1,44 \mathrm{~A}$ \\
\hline ALB (g/dL) & $1,72 \pm 0,46 \mathrm{~A}$ & $1,57 \pm 0,45 \mathrm{~A}$ & $1,66 \pm 0,49 \mathrm{~A}$ & $1,68 \pm 0,43 \mathrm{~A}$ & $1,74 \pm 0,49 \mathrm{~A}$ & $1,79 \pm 0,56 \mathrm{~A}$ & $1,55 \pm 0,57 \mathrm{~A}$ & $1,62 \pm 0,65 \mathrm{~A}$ & $1,63 \pm 0,60 \mathrm{~A}$ & $1,59 \pm 0,56 \mathrm{~A}$ \\
\hline GLB (g/dL) & $3,87 \pm 1,04 \mathrm{~A}$ & $3,48 \pm 1,08 \mathrm{~A}$ & $3,49 \pm 1,19 \mathrm{~A}$ & $3,47 \pm 0,86 \mathrm{~A}$ & $3,69 \pm 1,03 \mathrm{~A}$ & $3,57 \pm 1,30 \mathrm{~A}$ & $3,60 \pm 1,19 \mathrm{~A}$ & $3,30 \pm 1,42 \mathrm{~A}$ & $3,27 \pm 1,47 \mathrm{~A}$ & $3,35 \pm 1,27 \mathrm{~A}$ \\
\hline AST (U/L) & $71,05 \pm 20,53 \mathrm{~A}$ & $66,84 \pm 19,41 \mathrm{~A}$ & $66,58 \pm 22,97 \mathrm{~A}$ & $69,63 \pm 19,13 \mathrm{~A}$ & $69,30 \pm 19,80 \mathrm{~A}$ & $67,84 \pm 19,63 \mathrm{~A}$ & $70,53 \pm 21,47 \mathrm{~A}$ & $67,72 \pm 21,13 \mathrm{~A}$ & $74,53 \pm 32,09 \mathrm{~A}$ & $71,56 \pm 30,10 \mathrm{~A}$ \\
\hline GGT (U/L) & $48,53 \pm 13,75 \mathrm{~A}$ & $49,67 \pm 15,96 \mathrm{~A}$ & $51,26 \pm 32,62 \mathrm{~A}$ & $54,47 \pm 18,02 \mathrm{~A}$ & $49,77 \pm 21,02 \mathrm{~A}$ & $54,42 \pm 39,17 \mathrm{~A}$ & $55,00 \pm 36,76 \mathrm{~A}$ & $55,72 \pm 43,21 \mathrm{~A}$ & $54,84 \pm 34,32 \mathrm{~A}$ & $54,53 \pm 29,54 \mathrm{~A}$ \\
\hline
\end{tabular}

*valores na mesma linha seguidos de letras diferentes apresentaram diferença significativa no teste de ANOVA com comparação múltipla de Holm Sidak's, para dados com distribuição Normal, e Teste de Friedman, para dados que não seguiram o padrão Normal, com valor de p<0,05. 
Tabela 5. Valores médios e Desvio Padrão da Média para as variáveis estudadas na avaliação de perfil metabólico em ovelhas Santa Inês com Gestação Gemelar durante o periparto.

\begin{tabular}{|c|c|c|c|c|c|c|c|c|c|c|}
\hline \multirow{2}{*}{ Variável } & \multicolumn{10}{|c|}{ Semanas avaliadas } \\
\hline & $\operatorname{Pr} 5$ & Pr4 & Pr3 & Pr2 & Pr1 & PO & Po1 & Po2 & Po3 & Po4 \\
\hline GLI (mg/dL) & $49,92 \pm 9,01 \mathrm{~A}$ & $56,08 \pm 7,72 \mathrm{~A}$ & $53,83 \pm 7,04 \mathrm{~A}$ & $58,33 \pm 13,71 \mathrm{~A}$ & $63,92 \pm 8,34 \mathrm{~A}$ & $86,33 \pm 18,85 \mathrm{~B}$ & $67,58 \pm 9,92 \mathrm{AB}$ & $67,08 \pm 5,21 \mathrm{AB}$ & $64,92 \pm 8,49 \mathrm{AB}$ & $68,42 \pm 18,19 \mathrm{AB}$ \\
\hline $\mathrm{BHB}(\mathrm{mmol} / \mathrm{L})$ & $0,31 \pm 0,12 \mathrm{~A}$ & $0,32 \pm 0,12 \mathrm{~A}$ & $0,30 \pm 0,17 \mathrm{~A}$ & $0,53 \pm 0,26 \mathrm{~A}$ & $0,50 \pm 0,27 \mathrm{~A}$ & $0,73 \pm 0,23 \mathrm{~B}$ & $0,71 \pm 0,19 \mathrm{~B}$ & $0,62 \pm 0,26 \mathrm{AB}$ & $0,64 \pm 0,23 \mathrm{AB}$ & $0,43 \pm 0,15 \mathrm{AB}$ \\
\hline $\mathrm{Ca}(\mathrm{mg} / \mathrm{dL})$ & $7,75 \pm 1,46 \mathrm{~A}$ & $7,89 \pm 1,21 \mathrm{~A}$ & $7,22 \pm 1,11 \mathrm{~A}$ & $7,27 \pm 1,29 \mathrm{~A}$ & $6,28 \pm 1,29 \mathrm{~A}$ & $6,30 \pm 1,69 \mathrm{~A}$ & $5,07 \pm 1,18 \mathrm{~B}$ & $6,38 \pm 1,98 \mathrm{AB}$ & $5,59 \pm 1,83 \mathrm{AB}$ & $5,95 \pm 1,94 \mathrm{AB}$ \\
\hline $\mathrm{P}(\mathrm{mg} / \mathrm{dL})$ & $4,95 \pm 1,00 \mathrm{~A}$ & $4,69 \pm 1,21 \mathrm{~A}$ & $4,31 \pm 1,85 \mathrm{~A}$ & $3,71 \pm 1,66 \mathrm{~A}$ & $4,14 \pm 1,73 \mathrm{~A}$ & $3,82 \pm 0,71 \mathrm{~A}$ & $3,57 \pm 1,90 \mathrm{~A}$ & $3,61 \pm 1,36 \mathrm{~A}$ & $3,20 \pm 1,12 \mathrm{AB}$ & $3,24 \pm 0,99 \mathrm{AB}$ \\
\hline $\mathrm{Mg}(\mathrm{mg} / \mathrm{dL})$ & $2,03 \pm 0,60 \mathrm{~A}$ & $1,87 \pm 0,73 \mathrm{~A}$ & $2,17 \pm 0,57 \mathrm{~A}$ & $2,02 \pm 0,45 \mathrm{~A}$ & $1,86 \pm 0,59 \mathrm{~A}$ & $2,02 \pm 0,64 \mathrm{~A}$ & $1,64 \pm 0,52 \mathrm{~A}$ & $1,62 \pm 0,86 \mathrm{~A}$ & $1,59 \pm 0,64 \mathrm{~A}$ & $1,66 \pm 0,86 \mathrm{~A}$ \\
\hline $\mathrm{UR}(\mathrm{mg} / \mathrm{dL})$ & $16,17 \pm 7,96 \mathrm{~A}$ & $15,58 \pm 3,70 \mathrm{~A}$ & $19,00 \pm 5,91 \mathrm{AB}$ & $23,25 \pm 15,38 \mathrm{AB}$ & $29,75 \pm 17,51 \mathrm{AB}$ & $36,00 \pm 12,98 \mathrm{~B}$ & $37,00 \pm 8,44 \mathrm{~B}$ & $33,92 \pm 6,98$ B & $32,83 \pm 11,92 \mathrm{~B}$ & $30,83 \pm 11,29 \mathrm{AB}$ \\
\hline CRT (mg/dL) & $1,05 \pm 0,15 \mathrm{~A}$ & $1,10 \pm 0,08 \mathrm{~A}$ & $1,07 \pm 0,15 \mathrm{~A}$ & $1,10 \pm 0,22 \mathrm{~A}$ & $0,92 \pm 0,26 \mathrm{AB}$ & $0,94 \pm 0,23 \mathrm{AB}$ & $0,82 \pm 0,35 \mathrm{AB}$ & $0,72 \pm 0,22 \mathrm{~B}$ & $0,73 \pm 0,23 \mathrm{AB}$ & $0,74 \pm 0,21 \mathrm{AB}$ \\
\hline PROT (g/dL) & $5,27 \pm 1,56 \mathrm{~A}$ & $5,32 \pm 1,44 \mathrm{~A}$ & $5,21 \pm 1,05 \mathrm{~A}$ & $5,12 \pm 1,20 \mathrm{~A}$ & $5,50 \pm 0,61 \mathrm{~A}$ & $5,69 \pm 1,68 \mathrm{~A}$ & $4,75 \pm 1,48 \mathrm{~A}$ & $4,97 \pm 1,65 \mathrm{~A}$ & $4,31 \pm 1,53 \mathrm{~A}$ & $4,44 \pm 1,57 \mathrm{~A}$ \\
\hline ALB (g/dL) & $1,60 \pm 0,47 \mathrm{~A}$ & $1,54 \pm 0,56 \mathrm{~A}$ & $1,55 \pm 0,42 \mathrm{~A}$ & $1,57 \pm 0,50 \mathrm{~A}$ & $1,69 \pm 0,45 \mathrm{~A}$ & $1,55 \pm 0,48 \mathrm{~A}$ & $1,36 \pm 0,27 \mathrm{~A}$ & $1,36 \pm 0,46 \mathrm{~A}$ & $1,47 \pm 0,49 \mathrm{~A}$ & $1,26 \pm 0,59 \mathrm{~A}$ \\
\hline GLB (g/dL) & $3,67 \pm 1,29 \mathrm{~A}$ & $3,78 \pm 1,13 \mathrm{~A}$ & $3,66 \pm 0,73 \mathrm{~A}$ & $3,54 \pm 1,02 \mathrm{~A}$ & $3,81 \pm 0,75 \mathrm{~A}$ & $4,14 \pm 1,36 \mathrm{~A}$ & $3,39 \pm 1,35 \mathrm{~A}$ & $3,61 \pm 1,58 \mathrm{~A}$ & $2,84 \pm 1,31 \mathrm{~A}$ & $3,18 \pm 1,26 \mathrm{~A}$ \\
\hline AST (U/L) & $63,67 \pm 22,20 \mathrm{~A}$ & $60,08 \pm 22,89 \mathrm{~A}$ & $67,58 \pm 15,51 \mathrm{~A}$ & $63,83 \pm 19,70 \mathrm{~A}$ & $65,00 \pm 22,57 \mathrm{~A}$ & $76,08 \pm 30,89 \mathrm{~A}$ & $78,58 \pm 42,20 \mathrm{~A}$ & $80,67 \pm 30,33 \mathrm{~A}$ & $67,50 \pm 23,42 \mathrm{~A}$ & $68,58 \pm 30,79 \mathrm{~A}$ \\
\hline GGT (U/L) & $49,25 \pm 15,62 \mathrm{~A}$ & $46,67 \pm 17,91 \mathrm{~A}$ & $47,83 \pm 13,71 \mathrm{~A}$ & $44,75 \pm 12,08 \mathrm{~A}$ & $49,75 \pm 13,67 \mathrm{~A}$ & $48,42 \pm 16,35 \mathrm{~A}$ & $53,00 \pm 21,19 \mathrm{~A}$ & $55,00 \pm 22,00 \mathrm{~A}$ & $46,50 \pm 14,15 \mathrm{~A}$ & $48,67 \pm 16,74 \mathrm{~A}$ \\
\hline
\end{tabular}

*valores na mesma linha seguidos de letras diferentes apresentaram diferença significativa no teste de ANOVA com comparação múltipla de Holm Sidak's, para dados com distribuição Normal, e Teste de Friedman, para dados que não seguiram o padrão Normal, com valor de p<0,05. 
Quanto ao comportamento do perfil metabólico protéico, em se tratando dos níveis de Uréia, as semanas Pr1 a Po4 apresentaram valores superiores às semanas anteriores $(\mathrm{p}<0.05)$ no grupo GS, evidenciando uma elevação nos valores médios da variável ao longo do período avaliado. No grupo GG, a elevação dos níveis da variável se deu a partir da semana Pr3, onde o período pós-parto apresentou-se com valores estatisticamente superiores ao período pré-parto $(\mathrm{p}<0.05)$. Ao se comparar os grupos GS e GG, nenhuma diferença estatística foi notada entre as semanas avaliadas.

Com relação aos níveis de Creatinina, no grupo GS as duas primeiras semanas avaliadas foram estatisticamente diferente das demais semanas, evidenciando redução dos níveis médios da variável ao longo das semanas $(\mathrm{p}<0.05)$. Esta diminuição dos níveis séricos médios foi observada a partir da semana Pr3 no grupo GG ( $p<0.05)$. Apesar das diferenças observadas nas curvas de valores médios de Creatinina dos grupos GS e GG (figura 3B), não houve diferença estatística na comparação entre os grupos.

Na avaliação das variáveis Proteínas Totais, Albumina e Globulina, não foram observadas diferenças na comparação entre semanas, tanto para o grupo GS como GG. Semelhantemente, na comparação entre os grupos GS e GG, não foi constatada diferença entre as semanas avaliadas para as variáveis. na figura 3.

As curvas referentes aos níveis médios das variáveis do perfil metabólico protéico estão representadas

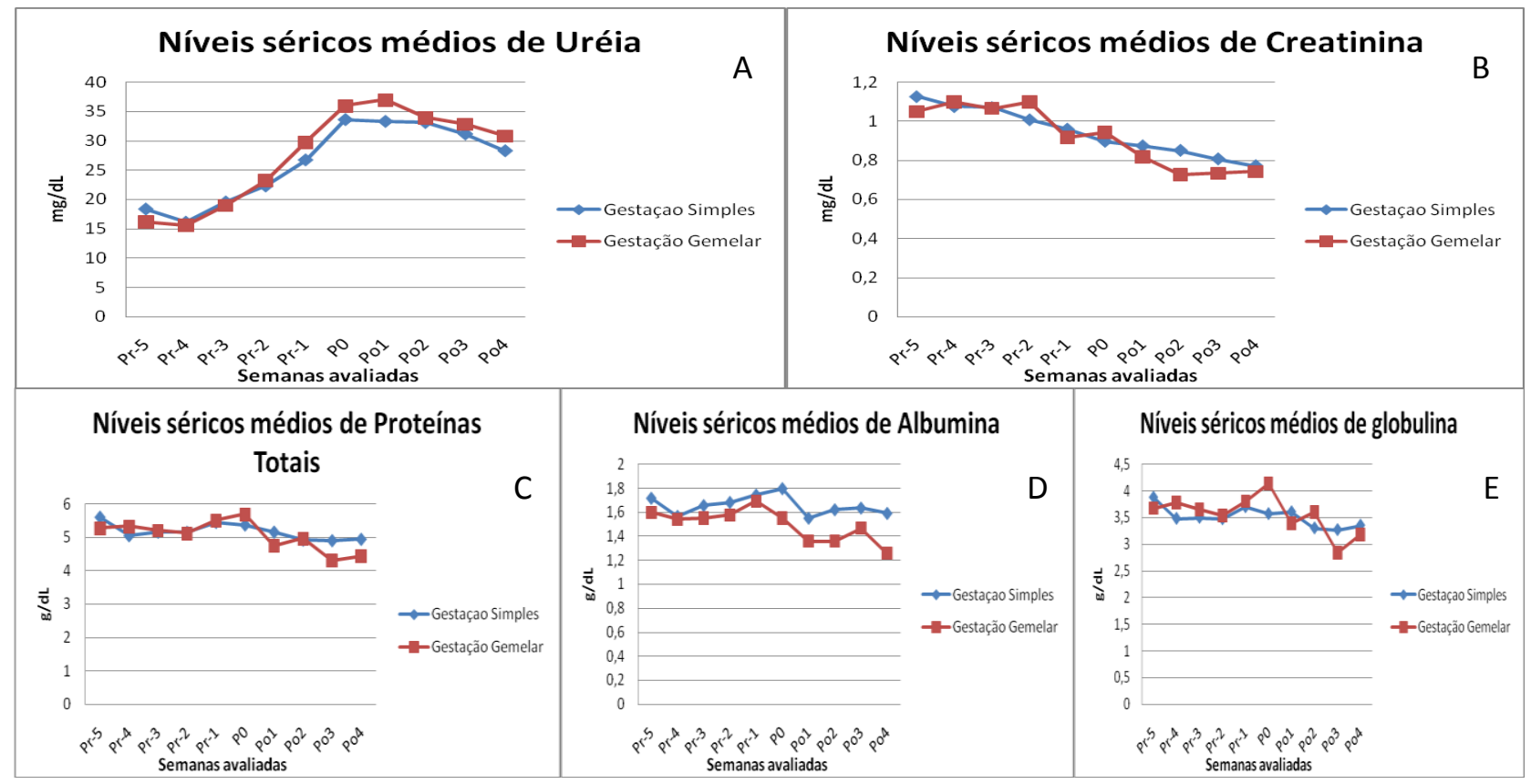

Figura 3- Perfil Metabólico Protéico - Níveis séricos médios das variáveis Uréia (A), Creatinina (B), proteínas Totais (C), Albumina (D) e Globulina (E) para os grupos Gestação Simples e Gemelar durante o periparto.

Na avaliação do perfil hepático, não se observaram diferenças entre semanas, tanto para os grupos GS e GG, nas variáveis AST e GGT. Na comparação entre grupos, não foram observadas diferenças. A figura 4 demonstra a representação gráfica do perfil hepático.

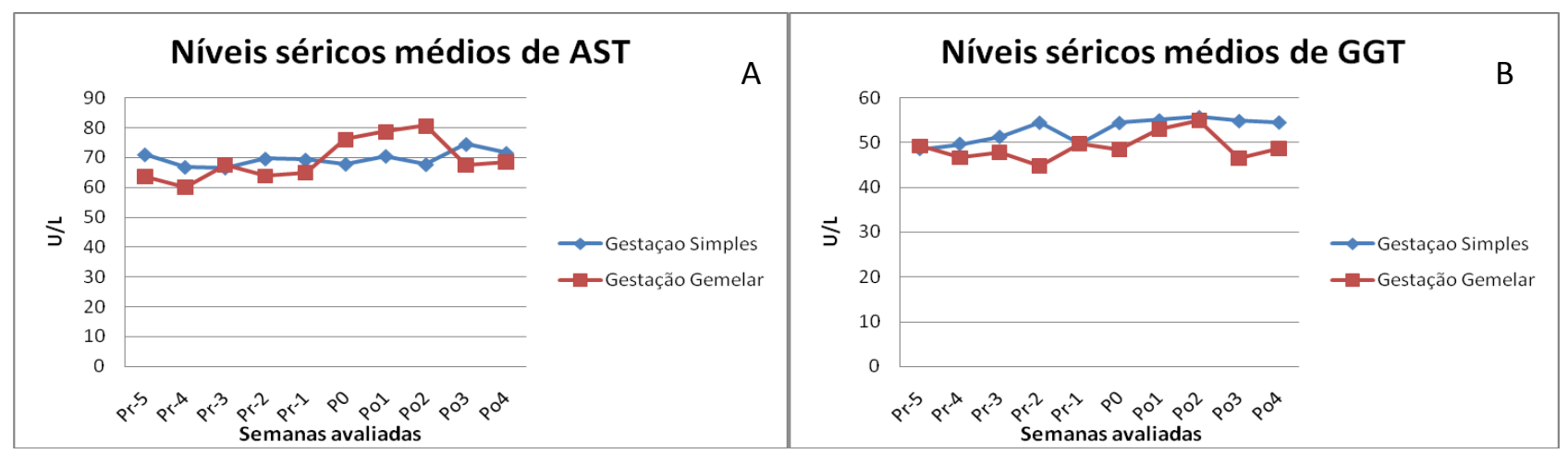

Figura 4- Perfil Hepático - Níveis séricos médios das variáveis AST (A) e GGT (B) para os grupos Gestação Simples e Gemelar durante o periparto. 
Na avaliação do comportamento do Escore Corporal em ambos os grupos, Gestação Simples e Gestação Gemelar, observou-se no primeiro grupo uma elevação na proporção de animais com EC2 concomitante à redução na porcentagem de animais com EC3 e EC4 (tabela 6), sendo o EC3 o predominante na ultima semana avaliada. A análise de escore corporal para o grupo GG demonstrou-se bem mais variável que em GS. Semelhantemente ao grupo GS, houve aumento da proporção de animais com EC2 e redução da proporção de animais com EC3 e 4, porem em GG, a redução do EC proporcionou a inversão na disposição destes, sendo evidenciado o EC2 como predominante na ultima semana avaliada (tabela 7).

Tabela 6 - Freqüência de Escore Corporal no grupo Gestação Simples.

\begin{tabular}{|c|c|c|c|c|c|c|c|c|c|c|}
\hline \multirow{2}{*}{$\begin{array}{l}\text { Escore } \\
\text { Corporal }\end{array}$} & \multicolumn{10}{|c|}{$\begin{array}{c}\text { Distribuição (em \%) de animais com respectivos valores de EC } \\
\text { ao longo das semanas avaliadas - Grupo GS }\end{array}$} \\
\hline & Pr5 & Pr4 & Pr3 & Pr2 & Pr1 & PO & Po1 & Po2 & Po3 & Po4 \\
\hline 1 & 0,00 & 0,00 & 0,00 & 0,00 & 0,00 & 0,00 & 0,00 & 0,00 & 0,00 & 0,00 \\
\hline 2 & 11,63 & 16,28 & 25,58 & 27,91 & 25,58 & 32,56 & 30,23 & 37,21 & 39,53 & 39,53 \\
\hline 3 & 81,40 & 76,74 & 65,12 & 65,12 & 69,77 & 62,79 & 65,12 & 60,47 & 60,47 & 60,47 \\
\hline 4 & 6,98 & 6,98 & 9,30 & 6,98 & 4,65 & 4,65 & 4,65 & 2,33 & 0,00 & 0,00 \\
\hline 5 & 0,00 & 0,00 & 0,00 & 0,00 & 0,00 & 0,00 & 0,00 & 0,00 & 0,00 & 0,00 \\
\hline
\end{tabular}

Tabela 7 - Freqüência de Escore Corporal no grupo Gestação Gemelar.

\begin{tabular}{cccccccccccc}
\hline \multirow{2}{*}{$\begin{array}{c}\text { Escore } \\
\text { Corporal }\end{array}$} & \multicolumn{8}{c}{ Distribuição (em \%) de animais com respectivos valores de EC } \\
\cline { 2 - 12 } & Pr5 & Pr4 & Pr3 & Pr2 & Pr1 & P0 & Po1 & Po2 & Po3 & Po4 \\
\hline 1 & 0,00 & 0,00 & 0,00 & 0,00 & 0,00 & 0,00 & 0,00 & 0,00 & 0,00 & 0,00 \\
2 & 8,33 & 8,33 & 0,00 & 16,67 & 33,33 & 66,67 & 50,00 & 50,00 & 41,67 & 66,67 \\
3 & 83,33 & 83,33 & 91,67 & 75,00 & 58,33 & 33,33 & 50,00 & 50,00 & 58,33 & 33,33 \\
4 & 8,33 & 8,33 & 8,33 & 8,33 & 8,33 & 0,00 & 0,00 & 0,00 & 0,00 & 0,00 \\
5 & 0,00 & 0,00 & 0,00 & 0,00 & 0,00 & 0,00 & 0,00 & 0,00 & 0,00 & 0,00 \\
& & & & & & & & & & \\
\end{tabular}

\section{DISCUSSÃO}

Independentemente do tipo gestacional, simples ou gemelar, o periparto é considerando um período crítico às ovelhas em fase produtiva, tendo em vista a grande demanda nutricional para o crescimento fetal (correspondente a 70-80\% nas ultimas seis semanas de gestação), parto, produção de leite e mantença (CONTRERAS et al., 2000). Qualquer desequilíbrio nesse momento, que ultrapasse a capacidade de adaptação do animal, pode ser fator determinante ao desenvolvimento de doenças metabólicas, muitas das vezes irreversíveis. Os resultados encontrados evidenciaram a grande variabilidade no comportamento dos parâmetros relacionados ao perfil metabólico avaliados, demonstrando a capacidade de adaptação fisiológica das ovelhas às demandas em cada momento do periparto, para garantir condições de homeostase.

A utilização, neste trabalho, de dosadores portáteis para mensuração das variáveis GLI e BHB mostrou-se muito prática e economicamente viável, permitindo a realização de tais dosagens no campo. Panousis et al. (2012), em uma avaliação de 193 ovelhas clinicamente saudáveis, ao comparar a dosagem de glicose e BHB entre técnica laboratorial convencional e o dosador portátil por fita reagente Precision Xceed ${ }^{\circledR}$ (Optimum Xceed® no Brasil), não observaram diferença estatística entre os testes, alem de identificarem altas sensibilidade (98.6\%) e especificidade (98.2\%) do segundo, indicando a eficácia do mesmo. Ao se considerar que o dosador portátil apresenta resultados imediatos (5 e 10 segundos para GLI e BHB, respectivamente), baixo custo por teste (R $\$ 1,00$ para GLI e $\mathrm{R} \$ 3,00$ para $\mathrm{BHB}$ ) e confiabilidade nos resultados apresentados, seu uso torna-se importante ferramenta ao profissional veterinário de campo, para o conhecimento do perfil metabólico energético e auxílio no exame clínico e levantamento de condição nutricional de rebanho. 
Na avaliação do perfil metabólico energético, observou-se, tanto no grupo GS quanto em GG, uma elevação nos níveis de glicose até a semana correspondente ao parto (P0). Valores crescentes nos níveis de glicose até o parto também foram observados por Oliveira et al. (2014). Semelhantemente, Cardoso et al. (2010), encontraram pico de glicemia correspondente à semana do parto. Em ambos os grupos, GS e GG, os níveis de glicose mantiveram-se constantes após o parto e dentro dos padrões de referência da espécie em todo o período avaliado, de acordo com Kaneko (2008), evidenciando um eficiente mecanismo regulatório das concentrações sanguíneas de glicose. Acredita-se que a elevação dos níveis da variável na semana do parto, se comparada às semanas precedentes, esteja relacionada ao aumento nos níveis de cortisol em decorrência do estresse do parto, hormônio estimulador da gliconeogênese, tornando a glicose mais biodisponível (Peixoto, 2011).

Ao se avaliar o comportamento da variável BHB, todos os valores médios encontrados ao longo dos períodos avaliados, em ambos os grupos, estiveram dentro dos valores de referência para a espécie (MERCK, 2005), demonstrando a manutenção das condições de homeostase. Mesmo em conformidade com os parâmetros de referência, o aumento nos níveis médios até a semana do parto e a manutenção de valores médios relativamente mais altos ao longo das semanas seguintes para os dois grupos, evidenciaram a mobilização de tecidos de reserva como mecanismo compensatório às demandas energéticas, em um possível estado de Balanço Energético Negativo, com a ocorrência de lipólise e partição de energia, refletindo em uma possível queda de insulina e conseqüentemente, aumento de glicose sérica, como evidenciada anteriormente. Observou-se tanto em GS quanto em GG a ocorrência de quadros de cetose subclínica, quadros estes que reforçam os achados referentes a elevação dos níveis de BHB. Em vacas leiteiras em produção, Duffield et al. (2009), descreveram uma proporção de até $25 \%$ de animais com quadro de cetose subclinica. No presente trabalho, foram encontradas $37 \%$ e $66 \%$ de cetose subclinica nos grupos GS e GG, respectivamente, demonstrando alta ocorrência de cetose subclinica em ovelhas durante o periparto. Tal achado ratifica a importância de adotar como rotina a dosagem de BHB tanto para auxiliar na nutrição quanto no diagnóstico precoce de doenças metabólicas.

Na avaliação do perfil metabólico protéico, observou-se que as variáveis PROT e ALB apresentarem-se abaixo do padrão de referencia para a espécie durante todas as semanas avaliadas, para ambos os grupos, GS e GG (KANEKO, 2008). De acordo com Gonzales (2008), a concentração de proteínas plasmáticas tende a sofrer queda fisiológica algumas semanas antes do parto, recuperando-se logo após o mesmo. Porem, neste trabalho, os níveis desta variável mantiveram-se baixos durante todo o período avaliado. Tendo em vista que os níveis de proteínas séricas estão intrinsecamente relacionados à nutrição, possíveis falhas na dieta fornecida aos animais podem justificar tal achado. Considerando como base o NRC (1985), a dieta fornecida aos ovinos (evidenciada na tabela 1), não atende às exigências nutricionais de energia e proteínas das fêmeas de ambos os grupos, após o parto, justificando, possivelmente, os níveis baixos de proteínas totais neste período. Fontes alimentares pobres em proteínas e energia desencadeiam o decréscimo nos níveis de proteínas circulantes no sangue, isso porque para os ruminantes, a energia disponível na dieta é essencial a constituição da microbiota rumenal, a qual dará origem à proteína microbiana utilizada pelo animal como fonte nutricional de aminoácidos, além da própria proteína disponível no alimento oferecido.

Da mesma forma, a albumina sofre interferência direta da dieta. Considerando o período estudado neste trabalho, os baixos níveis observados das duas variáveis apresentadas anteriormente, possivelmente devem-se à alta demanda protéica somada a uma deficiência na dieta fornecida aos animais. Acredita-se também que a albumina sérica possa decrescer em decorrência de sobrecarga hepática, por acúmulo de lipídios no fígado, e pelo aumento da demanda de aminoácidos para síntese de proteínas lácteas (Contreras, 2000). Infestações helmínticas gastrointestinais também podem ser responsáveis pelos baixos níveis de proteínas totais e albumina observados, justificando o achado durante todo o período avaliado. A espoliação desencadeada por alta infestação helmíntica, leva os animais parasitados a sofrerem déficit energético protéico, predispondo ao desenvolvimento de cetose e quadros clínicos de Toxemia da Gestação (ANDREWS, 1997). Tendo em vista que na propriedade o controle de endoparasitos era feito apenas com a utilização trimestral de anti-helmíntico, sem nenhum exame copro-parasitológico pré e pós tratamento, não foi possível saber a eficácia do controle parasitário adotado.

Os níveis de globulina encontrados mantiveram-se dentro dos padrões de referência da espécie, de acordo com KANECO (2008). Tendo em vista a migração de imunoglobulinas para a composição do colostro, esperava-se que os níveis da variável globulina apresentassem mais baixos na semana do parto, fato este que não foi observado. Segundo Contreras et al. (2000), baixos níveis de proteína na dieta desencadeiam queda nos níveis de albumina, sem alterações nos níveis de globulina, coincidindo com os resultados encontrados.

Quanto aos resultados obtidos na avaliação da variável Uréia, mesmo dentro dos parâmetros de normalidade para a espécie ovina, observaram-se níveis crescentes até a semana do parto em ambos os grupos estudados, os quais se mantiveram relativamente constantes nas semanas seguintes. Segundo Gonzales (2008), níveis aumentados de uréia podem estar relacionados a deficientes concentrações energéticas na dieta, dada a dificuldade de utilização dos compostos nitrogenados para produção de proteínas pela microbiota rumenal, fazendo com que a amônia seja absorvida mais intensamente pela parede do rúmen. Ao se avaliar os níveis de uréia conjuntamente ao BHB e proteínas totais, é possível afirmar que o aumento observado no primeiro 
parâmetro teve relação com o aumento da demanda nutricional nas fêmeas em estudo, associado a baixos níveis energético-protéicos na dieta oferecida, principalmente dada a maior exigência nutricional no pós parto, resultando em gliconeogênese hepática através de mobilização aminoácidos musculares (LHENINGER, 1995), com concomitante queda no escore corporal.

Contrariamente ao observado na variável uréia, os níveis de Creatinina apresentaram-se decrescentes ao longo das semanas avaliadas, tanto em GS quanto em GG. Em ambos os grupos, os valores médios encontrados mantiveram-se abaixo dos padrões de referência para ovinos. Baixos níveis de creatinina são compatíveis com quadros de insuficiência hepática e alterações musculares degenerativas (Gonzales, 2008). Tendo em vista que nenhum desses parâmetros foi observado nos animais estudados, não encontrou-se na literatura uma explicação plausível para tal perfil.

Quanto ao perfil metabólico mineral, observou-se que os valores encontrados para as variáveis Ca, $\mathrm{P}$ e Mg tanto em GS quanto em GG, estiveram abaixo dos índices de referência (KANEKO, 2008) para a espécie. Com exceção dos níveis médios de magnésio em GG, as demais variáveis minerais apresentaram níveis decrescentes ao longo das semanas avaliadas, em ambos os grupos estudados. Tendo em vista que os valores utilizados como referência para o perfil mineral na espécie ovina são proveniente de estudos desenvolvidos em países com condições climáticas e em raças distintas dos dados provenientes deste trabalho, somado a achados de outros trabalhos nacionais (Ribeiro et al., 2004; Oliveira et al., 2014), os quais também encontraram níveis minerais abaixo dos valores de referencia propostos, deduz-se que há necessidade de revisão nos valores de referência para minerais na espécie ovina sob condições de criação brasileiras, em especial a raça Santa Inês.

Cabe destacar também que a composição mineral da dieta oferecida aos animais em questão atenderam a exigência nutricional (segundo NRC, 1985), durante o período pré-parto, demonstrando-se insatisfatório apenas no pós parto para ambos os grupos, o que justifica a redução nos teores minerais observados ao longo das semanas avaliadas. Porem, mesmo em valores decrescentes, os níveis médios dos minerais mostraram-se abaixo dos valores de referencia ao longo de todas as semanas, reforçando o questionamento quanto aos padrões de referência propostos.

Segundo Gonzales (2000b), o cálcio é um mineral com alto controle endócrino, o que reflete em sua pequena variação sanguínea. Valores baixos de Ca refletem, portanto, a alta demanda metabólica, o que condiz com o período avaliado neste trabalho, tendo em vista a grande necessidade do mineral para composição do esqueleto fetal, ao final da gestação, alem da necessidade contrátil uterina ao parto, e produção de leite no pós parto. Quadros de hipocalcemia em ovelhas são mais freqüentes no terço final da gestação ate duas semanas pósparto, período este em que há grande mobilização para o esqueleto fetal e produção de leite, tendo em vista que o leite ovino apresenta concentração de Ca duas vezes maior se comparada a espécie bovina (Brozos et al., 2011). Na comparação entre os grupos GS e GG, somente a semana T0 apresentou diferença estatística quanto à variável Ca. Os níveis de Ca para as fêmeas com gestação gemelar $(6,30 \mathrm{mg} / \mathrm{dL})$ foram estatisticamente inferiores se comparados às com gestação simples $(6,79 \mathrm{ml} / \mathrm{dL})$, demonstrando maior demanda pelo mineral durante a semana do parto para o primeiro grupo, possivelmente pela maior necessidade para consolidação dos esqueletos fetais ou pela maior contratilidade uterina.

0 fósforo também é um mineral de grande importância na regulação metabólica. Sua regulação sanguínea é feita concomitantemente ao $\mathrm{Ca}$, porem seus níveis são mais variáveis, tendo em vista sua participação direta nos metabolismos energético e protéico, além de vários sistemas enzimáticos (Gonzales, 2000). Considerando-se os baixos níveis do referido mineral encontrados neste trabalho, é possível assumir que a suplementação oferecida aos animais foi insuficiente à demanda dos mesmos, principalmente no pós parto.

Semelhantemente ao Fósforo, os níveis de Mg circulante encontrados também apresentaram-se abaixo dos padrões de referência para a espécie ovina. Considerando-se que o mineral Mg tem seus níveis intrinsecamente relacionados à ingestão na dieta, os baixos valores encontrados também podem se relacionados ao desbalanço entre demanda e consumo. Segundo Contreras et al.(2000), em quadros em que há lipólise, decorrente da falta de energia, há uma tendência à redução nos níveis de $\mathrm{Mg}$, pelo seu consumo na mobilização de tecidos de reserva. Considerando-se o período avaliado neste trabalho, em que houve mobilização de tecido de reserva evidenciado pelo aumento nos níveis de BHB ao longo das semanas, tal mobilização pode justificar os baixos níveis de Mg observados.

$\mathrm{Na}$ avaliação do perfil hepático, através da atividade das enzimas AST e GGT, observou-se níveis estatisticamente constantes tanto em GS como em GG, mantendo-se dentro dos valores de referência para a espécie ovina durante todo o período avaliado (KANEKO,2008). Tais achados evidenciam um estado de higidez hepática, tendo em vista que níveis aumentados de AST e GGT indicam quadros de lipidose e cirrose hepática, compatíveis com o desenvolvimento de toxemia da gestação (Gonzales, 2008; Toma et al., 2010). Cal et al. (2009), observaram elevação na atividade de AST em ovelhas a partir de 130 dias de gestação com toxemia, níveis estes correlacionados positivamente com o grau de vacuolização no fígado, evidenciando que a enzima pode ser um bom indicador de alterações hepáticas decorrentes de quadros de toxemia da prenhez. Santos et al. (2011) também observaram aumento na atividade enzimática de AST e GGT em ovelhas diagnosticadas com quadros de toxemia da gestação, demonstrando a dosagem dessas variáveis como bons indicadores de alterações metabólicas onde há comprometimento hepático. 
Com exceção da variável cálcio, as demais variáveis analisadas não demonstraram diferença na comparação entre os grupos GS e GG. Levando-se em consideração o fato de a gestação gemelar estar intimamente relacionada à Toxemia da Gestação (SOARES et al., 2009; CAMPOS et al., 2010; SANTOS et al., 2011; MERCK, 2005), fato este justificado pela maior exigência nutricional na gemelaridade se comparado a gestações simples, a semelhança estatística em ambos os grupos avaliados com relação ao comportamento das variáveis metabólicas observadas neste trabalho demonstra a possível existência de outros fatores de maior importância para o surgimento da doença que o número de fetos gestantes. Mais estudos são, portanto, necessários para elencarem os fatores desencadeantes da toxemia da gestação, principalmente em se tratando de gestações gemelares.

Ao se avaliar os resultados encontrados quanto à variável Escore Corporal, observou-se, tanto em GS quanto em GG, uma redução no escore geral das ovelhas ao longo das semanas analisadas. A diminuição na porcentagem de animais com EC 3 e 4 deu lugar ao aumento no número de fêmeas avaliadas com o EC 2 . Tendo em vista a maior demanda nutricional no fim da gestação (em decorrência do crescimento fetal), parto e período de lactação (por mobilização energética para o útero e glândula mamaria, respectivamente), é aceitável e justificável a redução de escore observada neste trabalho, a qual é reafirmada, ainda, com os crescentes valores nos níveis de BHB e Uréia encontrados, indicando mobilização de tecido de reserva para mantença da homeostase das fêmeas avaliadas. Tais resultados ratificam os encontrados por Cardoso et al. (2010), os quais também observaram uma queda no escore corporal no parto e pós-parto em ovelhas, com valores abaixo de 3. 


\section{CONCLUSÃO}

O perfil metabólico mostrou ser uma ferramenta de grande valia para o auxílio na avaliação nutricional e possível diagnóstico precoce de doenças metabólicas, uma vez que evidenciou carências nutricionais e mobilização orgânica no intuito de manter condições de homeostase entre os animais avaliados.

Os níveis de Glicose, BHB, Cálcio, Fósforo, Uréia e Creatinina foram os que apresentaram maior variabilidade ao longo das semanas avaliadas, diferindo suas concentrações sanguíneas no terço final da gestação em relação à semana do parto e pós-parto. Baixos níveis das variáveis analisadas no perfil mineral e protéico, alem da elevação nos níveis de BHB e redução do escore corporal, evidenciaram que a dieta ofertada aos animais não atendeu à demanda nutricional no período avaliado, ocorrendo balanço energético negativo, cetose subclínica em uma considerável proporção dos animais, porem, em condições passíveis de compensação, tendo em vista a ausência de quadro clínico de doenças metabólicas nas fêmeas acompanhadas.

Os grupos Gestação Simples e Gestação Gemelar não diferiram ao longo das semanas avaliadas, quanto aos parâmetros mensurados no perfil metabólico. A ausência de diferenças estatisticamente significativas entre os grupos, retrata a capacidade de adaptação dos animais às necessidades específicas a cada fase de produção do periparto, porem, tais resultados abrem precedentes para novos estudos sobre a dinâmica de doenças metabólicas, uma vez que a literatura relaciona maior freqüência de tais patologias em fêmeas com gestações gemelares e, contrariamente ao relatado na mesma, não se observou grande diferenças entre os grupos estudados neste trabalho. 


\section{REFERÊNCIAS}

Andrews, A. 1997. Pregnancy toxaemia in the ewe. In Pratice. June. 19:306-314.

Ávila V.S., Fruet A. P. B., Barbieri M., Bianchini N. H. \& Dorr A. C. 2013. 0 retorno da Ovinocultura ao cenário produtivo do rio Grande do Sul. Rev. Elet. Em Gestão, Educação e Tecnologia Ambiental. Jun. Vol.11, 11:2419-2426.

Borges J. R. J., Moscardini A. R. C., Teixeira Neto A. R., Meirelles F., Ferreira I R., Gouvea L. V., Godoy R. F., Paludo G. R., Reis Júnior J., Ribeiro L., Pereira C. S., Eneias A. C., Fonseca E. F., Perecmanis S., Guedes K. M. R., Pitombo C. A., Franá R. O., Rajão M. \& Castro, M. B. 2007. Doenças dos ovinos no Brasil central: Distrito Federal e entorno. $4 \mathrm{p}$ Disponível em: HTTP://www.aleprycs.net/documentos/21709/30558/Borges,+Enferm+en+Brasil.pdf. Acesso em: 14 de agosto de 2014.

Brozos C., Mavrogianni V. S. \& Fthenaskys G. C. 2011. Treatment and control of peri-parturient metabolic diseases: Pregnancy toxemia, Hypocalcemia, Hypomagnesemia. Vet clin food anim., 27:105-113.

Cal L., Borteiro C., Benechi A., Rodasi E., Abreu M. N. \& Gonzales Montana J. R. 2009. Histological changes of the liver and metabolic correlates in ewes with pregnancy toxemia. Arquivo Brasileiro de Medicina veterinária e Zootencia. Vol.61, 2:306-312.

Campos A. G., Afonso J. A. B., Santos R. A., Mendonça C. L. \& Guimarães, J. A. 2010. Estudo Clínico-laboratorial da Toxemia da Prenhez em ovelhas: análise retrospectiva. Rev. Ciência Animal Brasileira, Goiânia, jul/set., Vol.11, 3:623-628.

Cardoso E. C., Oliveira D. F., Dourado A. P., Araujo C. V., Ortolani E. R. \& Brandão, F. Z. 2010. Peso e condição corporal, contagem de OPG e perfil metabólico sanguíneo de ovelhas da raça Santa Inês no periparto, criadas na região da baixada litorânea do Estado do Rio de Janeiro. Revista Brasileira de Ciência Veterinária, mai/ago, Vol.17, 2:77-82.

Contreras P., Wittwer F. \& Bohmwald H. 2000. Uso dos perfis metabólicos no monitoramento nutricional de ovinos. In: Gonzales F. H. D., Barcelos J. O., Ospina H. \& Ribeiro L. A. O. Perfil metabólico em ruminantes: seu uso em nutrição e doenças nutricionais. Porto Alegre, Brasil, Universidade Federal do Rio Grande do Sul. 108p.

Duffield T.F., Lissemore K.D., McBride B.W. \& Leslie, K.E. 2009. Impact of hyperketonemia in early lactation dairy cows on health and production. J. Dairy Sci. 92: 571-580.

Gonzales F. H. D. 2000. Indicadores sanguíneos do metabolismo mineral em ruminantes. In: Gonzales F. H. D., Barcelos J. O., Ospina H. \& Ribeiro L. A. O. Perfil metabólico em ruminantes: seu uso em nutrição e doenças nutricionais. Porto Alegre, Brasil, Universidade Federal do Rio Grande do Sul. 108p.

Gonzales, F. H. D. 2008. Bioquímica clínica. In: Gonzales F. H. D. \& Silva S. C. Patologia Clínica Veterinária/texto introdutório. Porto Alegre. Universidade Federal do Rio Grande do Sul. 342p.

Instituto Brasileiro de Geografia e Estatística - IBGE. Censo Agropecuário de 2006. Disponível em: http://www.ibge.com.br/estadosat/temas.php?sigla=df\&tema=censoagro. Acesso em 13 de junho de 2014.

Kaneko J. J., Harvey J. W. \& Bruss M. L. 2008. Biochemistry of Domestic. Animals. 6th ed. Academic Press, San Diego. 916p.

Lehninger A. L. 1995. Princípios de Bioquímica. 2.ed. São Paulo: Sarvier, 839p.

Merck Veterinary Manual. 2005. Pregnancy Toxemia in Ewes. 9ed. Merck \& Co., Inc. WhitehouseStation, NJ USA, 2712p.

McManus C., Louvandini H., Dallago B., Melo C. B. \& Seixas, L. 2010. Escore Corporal. INCT: Informação GenéticoSanitária da Pecuária Brasileira. Série Técnica: Genética. 31p. Disponível em: http://inctpecuaria.com.br/images/informacoes-tecnicas/serie tecnica escore corporal3.pdf. Acesso em: 28 de julho de 2014.

Melo D. B., Silva T. R., Medeiros J. M., Almeida F. C., Dantas E. S., Pessoa C. R. M. \& Simoes, S. V. 2009. Toxemia da Prenhez em caprinos: relato de surto. Ciência Animal Brasileira. Suplemento 1. Anais do VIII Congresso Brasileiro de Buiatria. p.123-127.

National Research Council (NRC). 1985. Nutrient requirement of sheep: 6ed. Washington: National Academy Press, 99p.

Oliveira R. P. M., Marudo A. H. P., Lima E. S. \& Oliveira F. F. 2014. Perfil metabólico de ovelhas Santa Inês em diferentes fases de gestação criadas em sistema semi-intensivo no estado do Amazonas. Ciência Animal Brasileira, Goiania, jan/mar, Vol.15, 1: 81-86.

Ortolani E. L. \& Benesi F. J. 1989. Ocorrência da toxemia da prenhez em cabras (Capra hicus, L) e ovelhas (Ovis Áries, L) criadas no estado de São Paulo, Brasil. Revista da Faculdade de medicina Veterinária e Zootecnia da USP. São Paulo, Vol.26, 2:229-234.

Panousis N., Brozos Ch., Karagiannis I., Giadinis N. D., Lafi S. \& Kritsepi-Konstantinou, M. 2012. Evaluation of Precision Xceed ${ }^{\circledR}$ meter for on-site monitoring of blood b-hydroxybutyric acid and glucose concentrations in dairy sheep. Research in Veterinary Science, Vol.93, p.435-439. 
Peixoto R. T. 2011. Perfil metabólico e hormonal de vacas F1 Holandês - Zebu durante o período pré e pós parto e sua relação com a reprodução. Dissertação de mestrado em Zootecnia- Escola de Veterinária, Universidade Federal de Minas Gerais, Belo Horizonte, 57p.

Pugh, D. G. 2002. Sheep \& Goat Medicine. $1^{\text {st }}$ ed. W.B. Saunders Company. 468p.

Radostits O. M., Gay C. C., Blood D. C. \& Hinchcliff K. W. 2002. Clínica veterinária: um tratado de doenças dos bovines, ovinos, suínos, caprinos e equinos. 9ed. Rio de janeiro: Guanabara Koogan, 1737p.

Ribeiro L. A. O., Gonzales F. H. D., Conceição T. R., Brito M. A., La Rosa V. L. \& Campos R. 2003. Perfil metabólico de borregas corriedale em pastagem nativa do Rio Grande do Sul. Acta Scientiae Veterinariae, 31 : 167 170.

Ribeiro L. A. O., Mattos R. C., Gonzales F. H. D., Wald V. B., Silva M. A. \& Rosa, V. L. 2004. Perfil metabólico de ovelhas Border Leicester x Texel durante a gestação e lactação. Revista Portuguesa de Ciências Veterinárias. Vol. 99, 551:155-159.

Santos F. C. O., Mendonça C. L., Silva Filho A. P., Carvalho C. C. D., Soares P. C. \& Afonso, J. A. B. 2011. Indicadores bioquímicos e hormonais de casos naturais de toxemia da prenhez em ovelhas. Pesq. Vet. Bras. Novembro, Vol.31, 11:974-980.

Schild, A. L. Cetose. In: Riet-Correa, F., Schild, A. L., Lemos, R. A. A., Borges, J. R. J. Doenças e Ruminantes e Equideos. 3a ed. Vol.2, Santa Maria - Pallotti. 2007.

Soares F. A. P., Borba Neto A. V., Guimarães J. A., Dantas A. C., Carvalho C. C. D., Marques A. V. S. \& Soares P. C. 2009. Metabolismo de indicadores preditivos de Toxemia da Prenhez em ovelhas Dorper no terço final da gestação, parto e pos-parto. Rev. Ciência Animal Brasileira, Suplemento 1, Anais do VIII Congresso Brasileiro de Buiatria, p. 197-203.

Toma H. S., Chiacchio S. B. \& Monteiro C. D. 2010. Aspectos clínicos, laboratoriais, necroscópicos e métodos diagnósticos da toxemia da gestação em pequenos ruminantes. Revista Científica Eletrônica de Medicina Veterinária. Janeiro. periódico semestral. Ano VIII, n14.17p.

Wittwer F. 2000. Diagnóstico dos desequilíbrios metabólicos de energia em rebanhos bovinos. In: Gonzales F. H. D., Barcelos J. O., Ospina H. \& Ribeiro L. A. O. Perfil metabólico em ruminantes: seu uso em nutrição e doenças nutricionais. Porto Alegre, Brasil, Universidade Federal do Rio Grande do Sul. 108p. 
ANEXOS

Anexo 1: Aprovação do projeto pelo Comitê de Ética da UNB

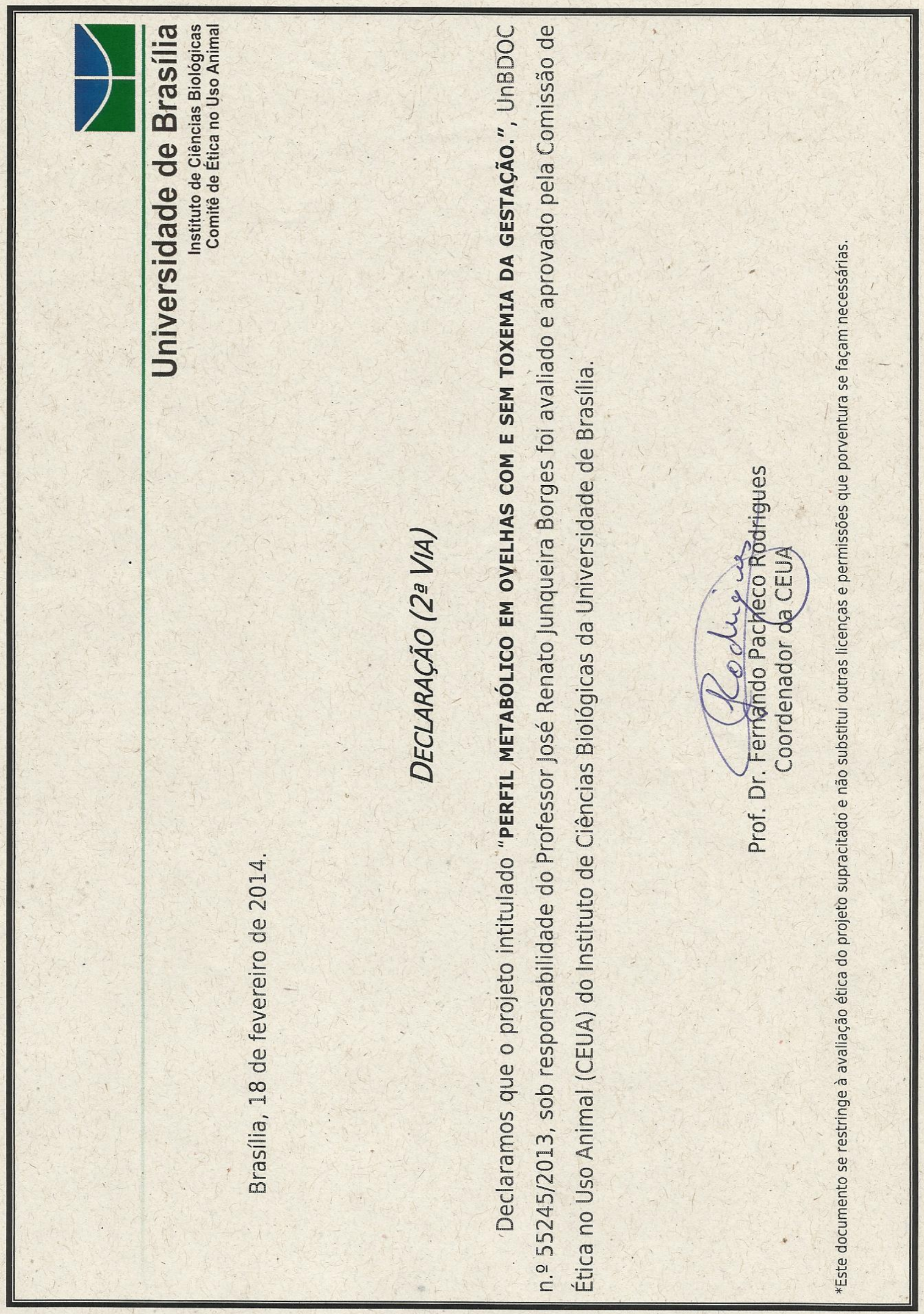




\section{Anexo 2: Termo de Consentimento livre e esclarecido - Fazenda Sanga Puitã}

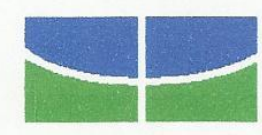

Universidade de Brasília

Faculdade de Agronomia e Medicina Veterinária

\section{Título da pesquisa:}

Perfil metabólico de ovelhas gestantes com e sem Toxemia da Gestação

\section{TERMO DE CONSENTIMENTO LIVRE E ESCLARECIDO}

Eu, Tánia Lauisa Maldaner abaixo assinado (a), autorizo a coleta de sangue dos meus animais e concordo em participar da referida pesquisa, realizada pelo Professor José Renato Junqueira Borges da Universidade de Brasília.

O trabalho tem como objetivo determinar o perfil metabólico de ovelhas no Peri-parto para identificação da Toxemia da Gestação.

Os pesquisadores manterão sigilo absoluto sobre as informações e assegurarão o meu anonimato quando da publicação dos resultados da pesquisa, além de me dar permissão de desistir, em qualquer momento, sem que isto me traga qualquer prejuízo, caso sinta qualquer constrangimento.

Fui informado(a) que posso indagar os pesquisadores se desejar fazer alguma pergunta sobre a pesquisa, pelo telefone: ( 61) 34687255 ou pelo e-mail irborges@unb.br,

ou no endereço Hospital Veterinário de Grandes Animais, Granja do Torto, Galpão 4, Asa Norte, Brasília - DF e que, se me interessar, posso receber os resultados da pesquisa quando forem publicados.

Esta pesquisa foi submetida ao comitê de ética visando atender às exigências éticas e científicas indicadas pela Comissão de Ética no Uso dos Animais da UnB. Este termo de consentimento será guardado pelos pesquisadores e, em nenhuma circunstância, ele será dado a conhecer a outra pessoa.

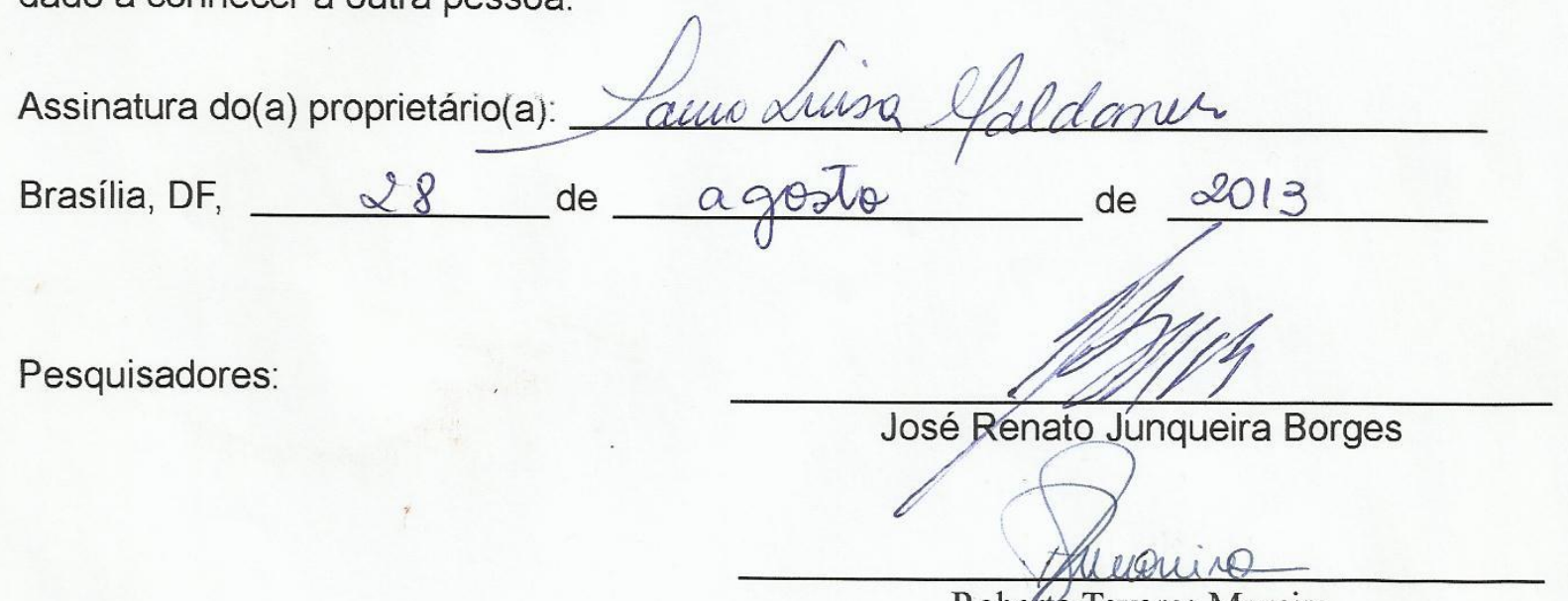

Robefta Tavares Moreira 